\title{
Effect of Pulsed Electric Fields on Enhanced Extraction and Cytotoxicity of Poly-Herbal Mixtures Against Estrogen Receptor-Positive Breast Cancer Cell Lines
}

Poompavai Sadasivam ( $\sim$ poompavai.hve@gmail.com )

Anna University Chennai Faculty of Electrical and Electronics Engineering

Gowri Sree Varadarajan

Anna University Chennai

\section{Research Article}

Keywords: Antioxidant activity, Breast cancer, Cell viability, Phenolic activity, Poly-herbal mixture, Pulsed Electric Fields

Posted Date: August 24th, 2021

DOI: https://doi.org/10.21203/rs.3.rs-828380/v1

License: (c) (i) This work is licensed under a Creative Commons Attribution 4.0 International License.

Read Full License 


\title{
Effect of Pulsed electric fields on enhanced extraction and cytotoxicity
} of poly-herbal mixtures against Estrogen receptor-positive breast cancer cell lines

\author{
Poompavai S, Gowri Sree V
}

Division of High Voltage Engineering, Department of Electrical and Electronics Engineering,

College of Engineering, Anna University, Chennai, India.

E-mail: poompavai.hve@gmail.com,gowri06@yahoo.com 


\begin{abstract}
:
The mixture of different bioactive constituents from plant extracts and several other natural products produces synergistic effects. This synergistic activity aids in treating and preventing various diseases by reducing the usage of conventional drugs. The present investigation aimed to study the effect of polyherbal formulations of selected plants (Turmeric, Pepper, Neem, Vinca rosea) on improved biological activity with and without pulsed electric fields(PEF). Selected plant extracts were combined in different proportions $(1 \%$ to $3 \%)$ to formulate a poly-herbal mixture. Ethanolic crude extracts were extracted by Soxhlet method and their phenolic activity and antioxidant activity were quantified. Further, to enhance the recovery of intracellular components, electrical fields of different parameters were used. The effect of PEF on formulated mixtures was compared with untreated extracts, which exhibited higher phenolic and antioxidant activity than untreated extracts. Out of all combinations, turmeric with pepper showed higher phenolic and antioxidant activity, and hence, these combinations were checked for their potential cytotoxicity against MCF-7 Estrogen breast cancer cells. In addition, different electrical ((EP1)High intensity,short duration \& (EP2)Low intensity,long duration) pulses were used to enhance the uptake of extracts into the cell membrane. Lowest cell viabilities of $19.41 \%$ (raw extract), $14.75 \%$ (pulsed extract),13.28\%(pulsed extract+EP1) and $9.982 \%$ (Pulsed extract+EP2) after $72 \mathrm{hrs}$ of treatment for $1000 \mu \mathrm{g} / \mathrm{ml}$ concentration of turmeric(97\%) and pepper(3\%) mixture was observed. This shows the potential of the synergistic effect of electrical pulses and poly-herbal mixture, achieving phenolic and antioxidant-rich extracts causing higher cell death. This technique can be used as an effective method to treat breast cancer avoiding undesirable side effects due to higher doses of synthetic drugs and single herb.
\end{abstract}

Keywords: Antioxidant activity, Breast cancer, Cell viability, Phenolic activity, Poly-herbal mixture, Pulsed Electric Fields

\title{
Introduction:
}

Phytochemicals are bioactive compounds found in fruits, vegetables, cereals, and other plant foods that could have therapeutic benefits in addition to basic nutrition, which includes lowering the risk of major chronic illnesses [1]. They offer a wide range of health benefits including antibacterial, antifungal, anticancer, antiviral, antithrombotic, lowering cholesterol and anti-inflammatory properties. Phytochemicals include phenolics, alkaloids, tannins, saponins, terpenoids and fiber that are capable of modulating metabolic processes resulting in the promotion of better health [2]. Several herbal plants with an ample number of potent bioactive compounds such as turmeric, aloe vera, neem, Vinca rosea, tulsi, mint, etc., have numerous health benefits. According to the World Health Organization (WHO), herbal plants are being used by over $80 \%$ of people worldwide to fulfill their basic health care needs [3]. About $60 \%$ of FDA-approved medications are derived from natural sources, particularly herbal plants, which contain a large number of bioactive chemicals, many of which have been used to develop new treatments [4]. Furthermore, it is estimated that only $10 \%$ of the nearly 1 million plant species discovered have been utilized to cure illnesses. Only 1 to $5 \%$ of the population is investigated for potential pharmacological efficacy against a variety of illnesses [5]. Further, phytochemicals offer a wide range of applications including pharmaceuticals, agrochemicals, flavors, fragrances, coloring agents, bio-pesticides and food additives [6]. Besides, plant extracts have lesser bioavailability and hence when used for their biological activity, only less amount of bioactive compounds is absorbed. From the literature, it is evident that a better therapeutic effect can be attained with a single multi-constituent formulation (i.e mixing different herbs, poly-herbal formulation). Due to the synergistic effect of different extracts, the poly-herbalism confers certain benefits that are not available in a single herbal extract or formulation $[7,8]$. 
In the present-day scenario, the demand for natural bioactive compounds is increasing due to their use in the functional food industries and pharmaceutical industries. Extraction of bioactive compounds from the plant sources safely and efficiently is very challenging for bio-based industries because the bioactive compounds remain inside the cell making it more complex to extract them easily [9]. Although conventional methods are used to extract these compounds, the pulsed electric field extraction technique is used to overcome the drawbacks of the existing methods as it not only provides a higher yield of bioactive compounds within a shorter period of time but also preserves the nutritional values of these compounds [10]. PEF technique is a non-thermal technology that utilizes the application of high-voltage short pulses to the cell membranes of plant tissues, resulting in the formation of pores that enhance the diffusion of solutes through the cell membranes, which in turn recovers the intracellular substances such as oil and other molecules of interest. PEF increases the extraction rates of juices, coloring agents, sugars, and other active ingredients, as well as the shelf life of the product $[11,12]$. Considering all these, the effect of poly-herbal formulations of selected herbs on improved biological activity with and without pulsed electric fields (PEF) was investigated. The total phenol contents, antioxidant activity and anticancer activity of poly-herbal mixtures are analyzed. Also, the potential of electrical pulse-mediated herbal therapy on ER-breast cancer cell lines is investigated.

\section{Materials and Methods:}

\section{Preparation of plant extracts:}

Commercially available dried rhizomes of turmeric, dried roots of Vinca rosea and black pepper are purchased from an organic store in Chennai, India. Fresh neem leaves are collected from Anna University Campus, Chennai, India, and washed thoroughly with distilled water to remove dirt and impurities and shade dried for 10 days. All the samples are powdered using an electric mixer and stored for further use. $25 \mathrm{~g}$ of powdered samples are taken into a thimble and placed in a Soxhlets apparatus, with 100ml of solvent (ethanol). The extraction process continues for about seven hours. After completion of extraction, the rotary evaporator is used to obtain a crude dried extract. The obtained extracts are stored in $4^{\circ} \mathrm{C}$ in airtight containers and are taken for further use.

\section{Preparation of Poly-herbal mixtures:}

The obtained extracts are combined with each other in different proportions (1\% to 3\%) to form polyherbal mixtures. The systematic algorithm followed for the combination of extracts is illustrated in Figure 1. The impact of the pulsed electric fields on the phenol contents, antioxidant activity and anticancer activity of all the mixtures is assessed quantitatively.

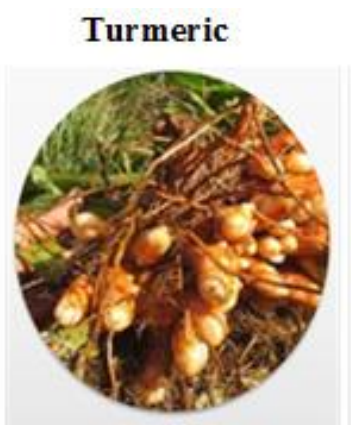

99\% Turmeric $+1 \%$ Pepper $\mathbf{9 8} \%$ Turmeric $+\mathbf{2} \%$ Pepper 97\% Turmeric $+3 \%$ Pepper $99 \%$ Turmeric $+1 \%$ Neem $98 \%$ Turmeric $+2 \%$ Neem $\mathbf{9 7} \%$ Turmeric $+3 \%$ Neem $\mathbf{9 9} \%$ Turmeric $+1 \%$ Vinca $\mathbf{9 8} \%$ Turmeric $+\mathbf{2} \%$ Vinca $\mathbf{9 7} \%$ Turmeric $+\mathbf{3} \%$ Vince

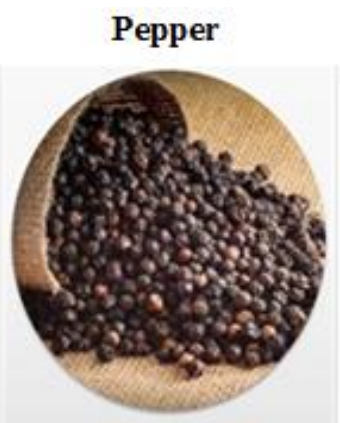

$99 \%$ Pepper $+1 \%$ Turmeric $98 \%$ Pepper $+2 \%$ Turmeric 97\% Pepper $+3 \%$ Turmeric $99 \%$ Pepper $+1 \%$ Neem $98 \%$ Pepper $+2 \%$ Neem 97\% Pepper $+3 \%$ Neem $99 \%$ Pepper $+1 \%$ Vinca $\mathbf{9 8} \%$ Pepper $+2 \%$ Vinca $97 \%$ Pepper $+3 \%$ Vinca

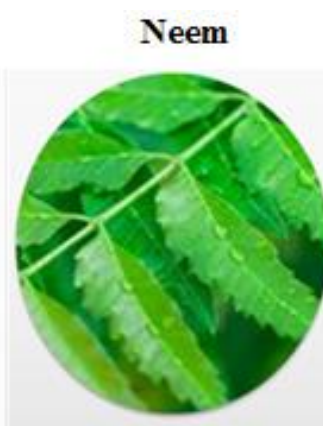

$99 \%$ Neem $+1 \%$ Turmeric $98 \%$ Neem $+2 \%$ Turmeric $97 \%$ Neem $+3 \%$ Turmeric $99 \%$ Neem $+1 \%$ Pepper $98 \%$ Neem+ $2 \%$ Pepper $97 \%$ Neem $+3 \%$ Pepper $99 \%$ Neem $+1 \%$ Vinca $98 \%$ Neem $+2 \%$ Vinca $97 \%$ Neem $+3 \%$ Vinca
Vinca rosea

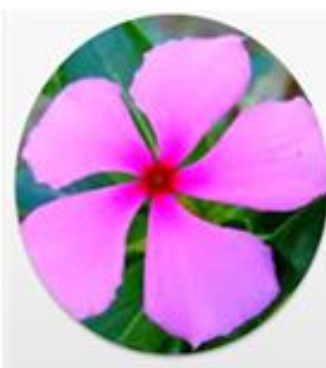

$99 \%$ Vinca $+1 \%$ Turmeric $98 \%$ Vinca $+2 \%$ Turmeric $\mathbf{9 7} \%$ vinea $+3 \%$ Turmeric $99 \%$ Vinca $+1 \%$ Pepper $98 \%$ Vinca $+2 \%$ Pepper $97 \%$ Vinca $+3 \%$ Pepper $99 \%$ Vinca $+1 \%$ Neem $98 \%$ Vinca $+2 \%$ Neem $97 \%$ Vinca $+3 \%$ Neern

Fig. 1. Algorithm for the combination of extracts 


\section{Application of Pulsed Electric Fields:}

Different concentrations of ethanolic crude extracts are subjected to varying electric fields from $2.5 \mathrm{kV} / \mathrm{cm}$ to $7.5 \mathrm{kV} / \mathrm{cm}$ with constant pulse interval and pulse duration as $100 \mathrm{~ms}$ and $100 \mu$ s respectively for 99 pulses. BTX ECM 830 Electroporator (Harvard apparatus, USA) is used to generate varying electric fields. The electrical pulses are applied to the extracts placed in the cuvette with the electrode gap of $4 \mathrm{~mm}$ and are placed in a chamber that holds $800 \mu \mathrm{l}$ of the sample. After applying the electrical pulse to the extracts, the extracts are transferred to vials and used for further analysis [13].

\section{Total phenol contents:}

Natural phytophenols are considered as antioxidant compounds having the ability to damage free radicals in organisms related to their bioactivity to inhibit lipoxygenase, scavenge free radicals and chelate metals [14]. Here, the total phenolic content of the extracts is determined by using the Folin-Ciocalteu reagent by Slinkard and Singleton method. Standard Gallic acid is used for calibration and experimentation. $1 \mathrm{ml}$ extract is mixed with $0.5 \mathrm{ml}$ reagent diluted with $7 \mathrm{ml}$ deionized water. $3 \mathrm{ml} \mathrm{of} \mathrm{Na}_{2} \mathrm{CO}_{3}(2 \%)$ is added after 3 minutes and then the mixture is allowed to stand for $2 \mathrm{~h}$ with intermittent shaking. After incubation, the absorbance is measured by using a UV-Visible spectrophotometer at $750 \mathrm{~nm}$ wavelength. The amount of phenols is determined from the standard Gallic acid graph $\left(\mathrm{R}^{2}=0.996\right)$. The total phenols are expressed as $\mathrm{mg} / \mathrm{g}$ Gallic acid equivalent using the standard curve equation:

$$
\mathrm{Y}=0.0024 \mathrm{x}+0.0925, R^{2}=0.996,
$$

where, Y- Absorbance at $760 \mathrm{~nm}, \mathrm{x}$ - Total phenol in the extracts. The above equation is obtained by considering various concentrations of standard solution, as it increases with the linear fit equation. Further, the total phenol content of the extract is calculated in terms of Gallic Acid Equivalent (GAE),

$$
C=c \times \frac{V}{m}
$$

where $\mathrm{C}$ is the total phenolic compound in $\mathrm{mg} / \mathrm{g}$. of extract, $\mathrm{c}$ is the concentration of Gallic acid from the calibration curve, $\mathrm{V}$ is the volume of the extract in $\mathrm{ml}, \mathrm{m}$ is the weight of extracts in $\mathrm{g}$. The effect of pulsed electric fields on the total phenol content of each extract is observed $[13,15,16]$.

\section{Antioxidant activity:}

The antioxidant activities of all the extracts are evaluated by the free radical scavenging effect on 1,1diphenyl-2-picrylhydrazyl (DPPH) radical. The technique suggested by Akowuah et al. [15] is used to determine this value, in which the DPPH free radical is decreased in the presence of an antioxidant molecule, results in a colourless ethanol solution. $3 \mathrm{~mL}$ absolute methanol and $0.3 \mathrm{~mL}$ DPPH radical solution are added to $0.5 \mathrm{~mL}$ of the sample $(0.5 \mathrm{mM}$ in methanol). For an hour, the mixture is well mixed and stored in the dark place. DPPH and methanol are mixed to make the control. Microplate reader spectrophotometers are used to measure the absorbance at $517 \mathrm{~nm}$ (color changes from deep violet to light yellow). Samples are measured in three replicates and the percentage inhibition of DPPH is calculated by the formula given below $[13,15,16]$.

$$
\% \text { inhibition of DPPH }=\frac{A_{\text {control }}-A_{\text {sample }}}{A_{\text {control }}} \times 100 \%
$$

where $A_{\text {control }}$ is the absorbance of the control and $A_{\text {sample }}$ is the absorbance of the sample.

\section{Cell culture and cell viability assay:}

The estrogen receptor human breast cancer MCF-7 cell lines are procured from National Centre for Cell Sciences, Pune (NCCS). These cells are cultured as a monolayer in Dulbecco's modified Eagle's medium (DMEM) with $10 \%$ FBS, penicillin $(100 \mathrm{U} / \mathrm{ml})$, and streptomycin $(100 \mu \mathrm{g} / \mathrm{ml})$ in a humidified atmosphere of $50 \mu \mathrm{g} / \mathrm{ml} \mathrm{CO} 2$ at $37^{\circ} \mathrm{C}$. 


\section{Test Procedure:}

The cell suspension is taken in the electroporation cuvette with an electrode gap of 4mm. BTX ECM 830 Electroporator (Harvard apparatus, USA) is used to generate unipolar square pulses with $1 \mathrm{~Hz}$ frequency. Cultured MCF-7 cell lines are exposed to the following treatments as followed in our previous work,

- Raw extract only,

- Pulsed extract only,

- Pulsed extract + Electric pulses of high intensity, low duration $(\mathrm{EP} 1=1200 \mathrm{~V} / \mathrm{cm}, 100 \mu \mathrm{s}, 8$ pulses $)$

- Pulsed extract + Electrical pulses of low intensity high duration $(E P 2=500 \mathrm{~V} / \mathrm{cm}, 20 \mathrm{~ms}, 8$ pulses $)$

Above experiments are done for different concentrations of sample at 1000, 500, 250, 125, 62.5, 31.2, $15.6,7.8 \mu \mathrm{g} / \mathrm{ml}$. Hence, a dose-dependent viability study is done in this study for each treatment [15-17].

\section{Statistical Analysis}

Minitab 19 statistical package is used to perform statistical analysis. Data is checked for normality and homoscedasticity assumptions. All the experiments were done in triplicates. Statistical significance for cell viability study is assessed by using Analysis of variance (ANOVA), followed by Tukey's posthoc test for multiple comparisons. A probability value $(\mathrm{p}<0.01)$ is considered statistically significant for the whole study [18].

\section{Results and discussions:}

Our work includes the study of enhanced extraction of phytochemicals from poly-herbal mixtures with the study of their cytotoxic activity against ER-positive MCF-7 breast cancer cell lines using electrical pulses.

\section{Effect of PEF on Poly-herbal mixtures:}

The effect of pulsed electric field on total phenol contents and antioxidant activity of combined extracts are presented in the following sections

\section{- Turmeric and its Combination:}

Despite all the positive effects of turmeric, it possesses a major limitation of poor bioavailability due to poor solubility, poor absorption and extensive metabolic conversion of the molecule. Usually, pepper is used as a natural enhancer to increase the bioavailability of turmeric. A study showed that pairing $1 \%$ of piperine with $99 \%$ of curcumin increased the bioavailability of curcumin by 2000 percent [19]. In this study, turmeric is mixed with neem, pepper and Vinca rosea extracts in different proportions of $1 \%, 2 \%$ and 3\% for five different concentrations. The effect of PEF on these combination extracts is assessed and compared with untreated extracts. The results are based on the experiments performed in triplicates. Error bars are calculated using standard error. Total phenol contents are obtained by using Folin-Ciocalteau reagent assay. When turmeric is mixed with pepper extracts and exposed to different electric fields of $2.5 \mathrm{kV} / \mathrm{cm}$ to $7.5 \mathrm{kV} / \mathrm{cm}$, an increase of $56.56 \%$ for sample A (99\% of turmeric $+1 \%$ of pepper extract), and $52.43 \%$ increase for sample B (98\% of turmeric $+2 \%$ of pepper extract), and $47.31 \%$ increase for sample C ( $97 \%$ of turmeric $+3 \%$ of pepper extract), was observed. The highest phenol content of 241.26 $\mathrm{mg} \mathrm{GAE} / \mathrm{ml}$ is noted for sample $\mathrm{C}$; this can be due to the effectiveness of pepper on enhancing turmeric extract. The effects of PEF on combined (turmeric and pepper) extracts are presented in Figure. 2(A). Further, for other combinations (turmeric with neem), an increase of $62.65 \%$ is observed for sample D ( $99 \%$ of turmeric $+1 \%$ of neem extract), an increase of $54.11 \%$ for sample E $(98 \%+2 \%)$ and an increase of $55.10 \%$ for sample $\mathrm{F}(97 \%+3 \%)$ is observed between untreated and PEF treated extracts. The effect of PEF on combined (turmeric and neem) extracts is illustrated in Figure. 2(B). Similarly, when turmeric is mixed with Vinca rosea extracts, a similar trend is followed, when treated with PEF as in Figure. 3(A). 


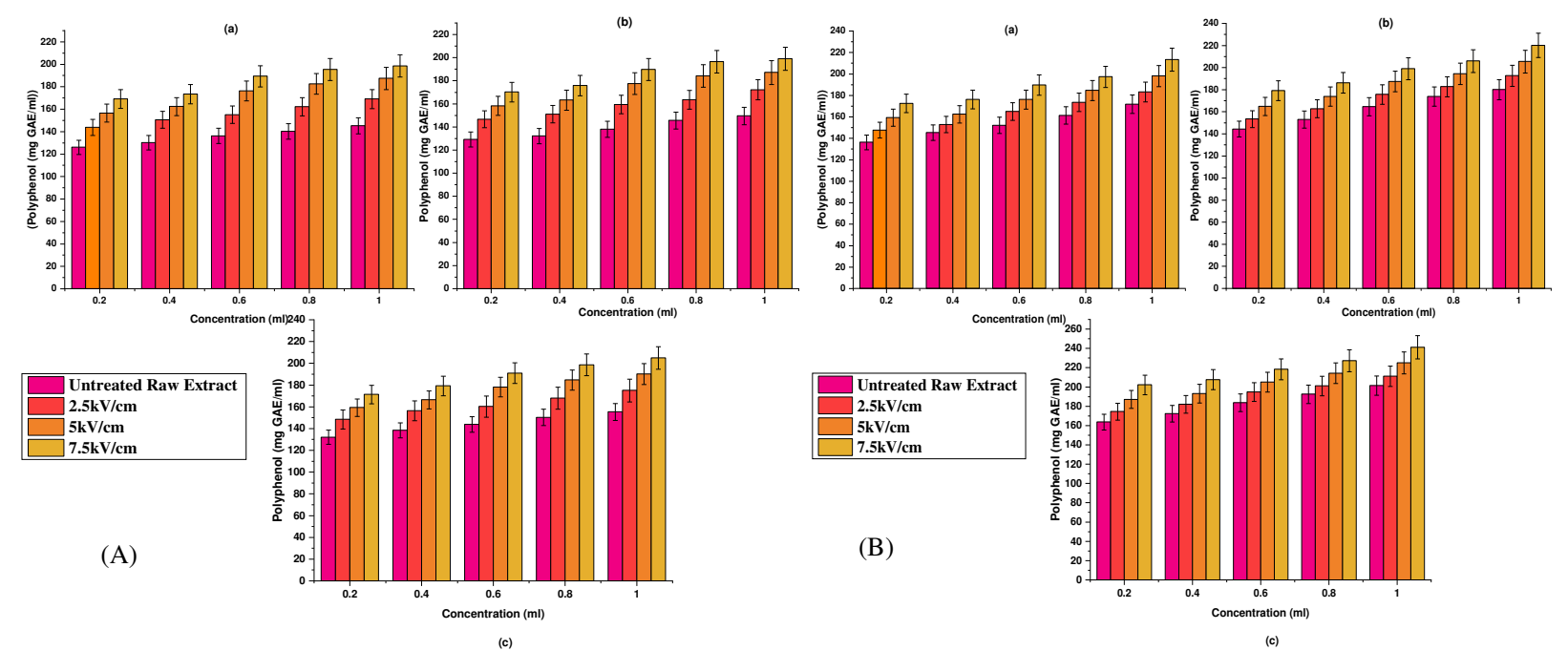

Fig. 2 (A) Effect of pulsed electric field on phenolic activity of ((a) 99\% + 1\% (b) $98 \%+2 \%$ and (c) $97 \%+3 \%$ ) turmeric + pepper combination extracts. Fig. 2(B). (right) Effect of pulsed electric field on phenolic activity of ((a) $99 \%+1 \%$ (b) $98 \%+2 \%$ and (c) $97 \%+$ 3\%) turmeric + neem combination extracts

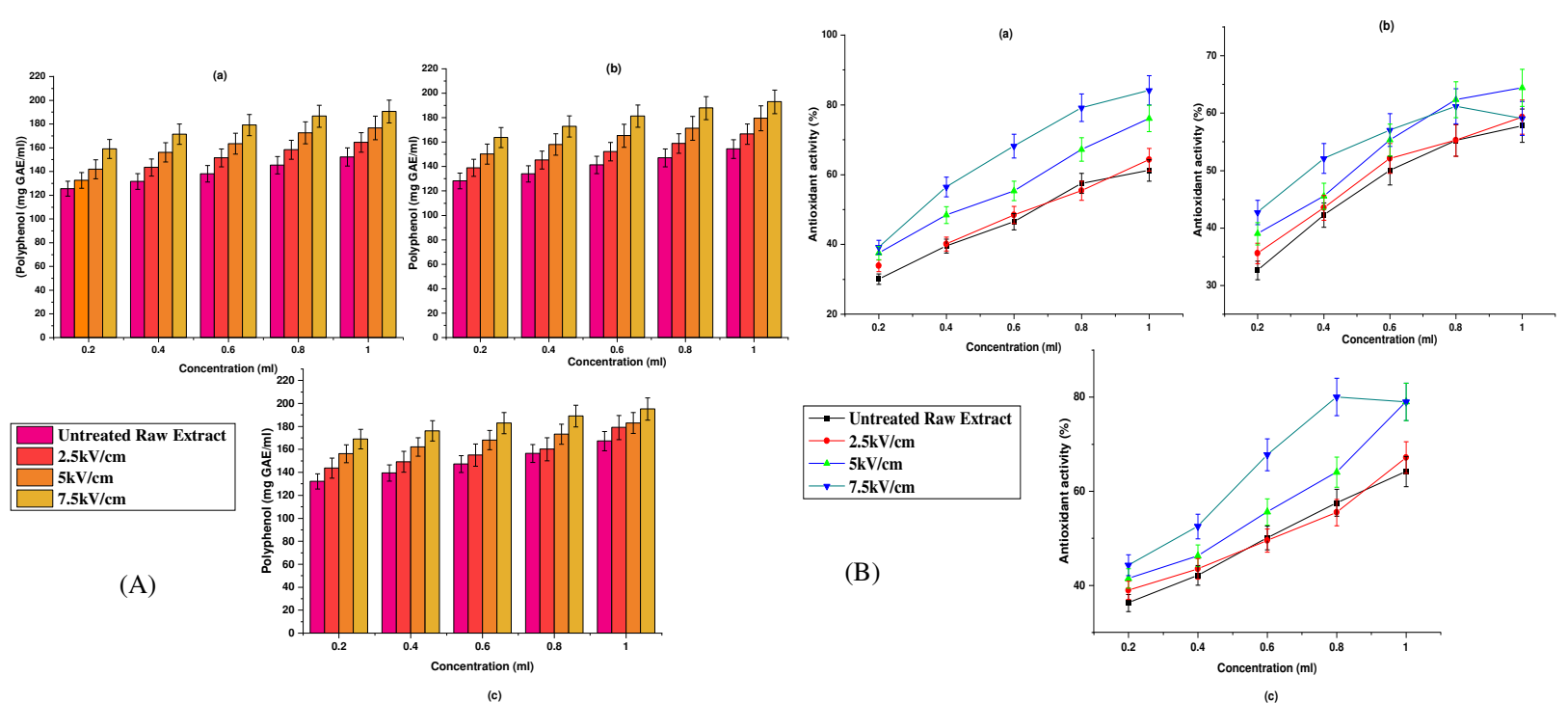

Fig. 3(A) Effect of pulsed electric field on phenolic activity of ((a) $99 \%+1 \%$ (b) $98 \%+2 \%$ and (c) $97 \%+3 \%)$ turmeric + Vinca rosea combination extracts. Fig. 3(B). Effect of pulsed electric field on antioxidant activity of ((a) $99 \%+1 \%$ (b) $98 \%+2 \%$ and (c) $97 \%+3 \%)$ turmeric + neem combination extracts
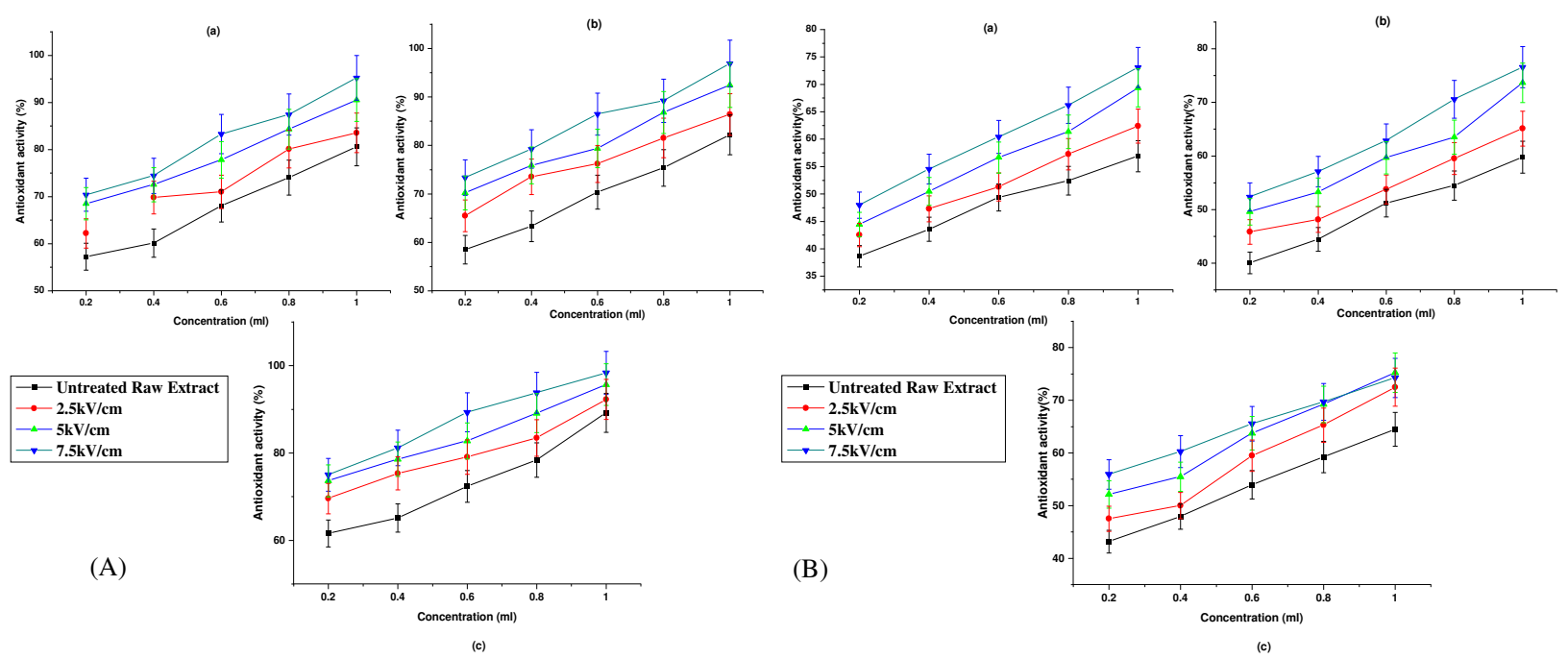

Fig. 4(A) Effect of pulsed electric field on antioxidant activity of ((a) 99\% +1\% (b) $98 \%+2 \%$ and (c) $97 \%+3 \%)$ turmeric + pepper combination extracts Fig. 4(B). Effect of pulsed electric field on antioxidant activity of ((a) $99 \%+1 \%$ (b) $98 \%+2 \%$ and (c) $97 \%+3 \%)$ turmeric + Vinca rosea combination extracts 
When experimented with turmeric and neem extracts, PEF treated extracts exhibit the highest antioxidant activity $(84.16 \%$ ), while untreated extract shows the lowest antioxidant activity of $30.06 \%$. As the concentration of extracts increases from $0.2 \mathrm{ml}$ to $1 \mathrm{ml}$, antioxidant activity increase gradually from $30.06 \%$ to $84.16 \%$ for $1 \mathrm{ml}$ concentration and $7.5 \mathrm{kV} / \mathrm{cm}$, which is about $\sim 6$ times more than untreated extracts. But, for (98\% of turmeric $+2 \%$ of neem extract) extracts, untreated extracts exhibit $32.62 \%$, whereas treated with $5 \mathrm{kV} / \mathrm{cm}$, extracts exhibit $64.4 \%$ but when treated with $7.5 \mathrm{kV} / \mathrm{cm}$, it has reduced to $59.066 \%$. Hence, there is an increase of $93.41 \%$ between untreated and treated extracts and a decrease of $8.27 \%$ between treated extracts. Similarly, for $(97 \%$ of turmeric $+3 \%$ of neem extract) extracts, untreated extracts exhibit $36.27 \%$, whereas treated with $5 \mathrm{kV} / \mathrm{cm}$, extracts exhibit $80.05 \%$ antioxidant activity but when treated with $7.5 \mathrm{kV} / \mathrm{cm}$, it has reduced to $79 \%$. Hence, there is an increase of $120.66 \%$ between untreated and treated extracts and a decrease of $1.30 \%$ between treated extracts. Similarly, when turmeric is mixed with pepper and Vinca rosea, the same pattern has been followed as illustrated in Figure. 4(A) and (B). Total phenol contents and antioxidant activity increase for increasing concentrations and increasing applied electric fields.

\section{- Pepper and its Combination}

Pepper is naturally known as a bio-enhancer, it can enhance the activity of the extracts. Piperine, the major alkaloid present in the pepper can increase the bioavailability of many nutrients by metabolizing the enzymes [20]. When pepper is combined with turmeric extracts, the highest phenol content of 128.3 $\mathrm{mg} \mathrm{GAE} / \mathrm{ml}$ is observed, further, when treated with PEF, it exhibited $162.01 \mathrm{mg} \mathrm{GAE} / \mathrm{ml}$ phenol contents.
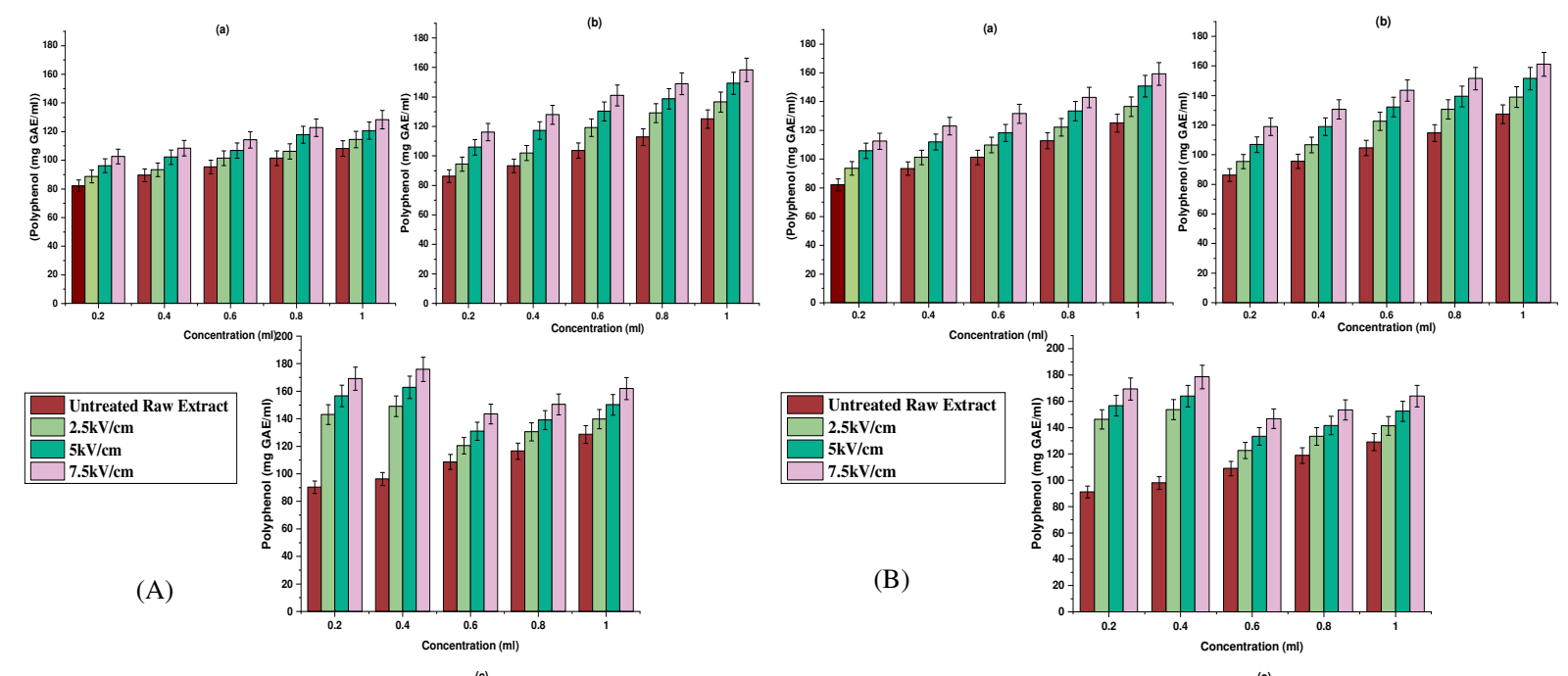

Fig. 5(A) Effect of pulsed electric field on phenolic activity of ((a) $99 \%+1 \%$ b) $98 \%+2 \%$ and (c) $97 \%+3 \%)$ pepper + turmeric combination extract. Fig. 5(B). Effect of pulsed electric field on phenolic activity of ((a) $99 \%+1 \%(b) 98 \%+2 \%$ and (c) $97 \%+3 \%)$ pepper + neem combination extracts

Similarly, when mixed with neem, the highest phenol content of $164.14 \mathrm{mg} \mathrm{GAE} / \mathrm{ml}$ is observed for PEF treated extracts, whereas untreated extracts possess only $82.33 \mathrm{mg} \mathrm{GAE} / \mathrm{ml}$ phenols. Hence, PEF treated extracts exhibit phenol contents two times more than untreated extracts as illustrated in Figure. 5(A). Other mixture of pepper with neem and Vinca rosea extracts also follow a similar pattern as illustrated in Figure. 5(B) and Figure. 6(A) Out of all combinations, pepper when mixed with neem and treated with $7.5 \mathrm{kV} / \mathrm{cm}$ fields possesses the highest phenol contents of $164.14 \mathrm{mg} \mathrm{GAE} / \mathrm{ml}$. In the case of antioxidant activity, when pepper is mixed with turmeric, it exhibits its highest antioxidant activity of $92.14 \%$ when treated with PEF $(7.5 \mathrm{kV} / \mathrm{cm})$, while untreated extract shows the lowest antioxidant activity of $51.2 \%$ as presented in Figure.6(B). As the concentration of extracts increases from $0.2 \mathrm{ml}$ to $1 \mathrm{ml}$, antioxidant activity increases gradually from $51.2 \%$ to $92.14 \%$ for $1 \mathrm{ml}$ concentration and $7.5 \mathrm{kV} / \mathrm{cm}$, which is about $\sim 1.5$ times more than untreated extracts. 

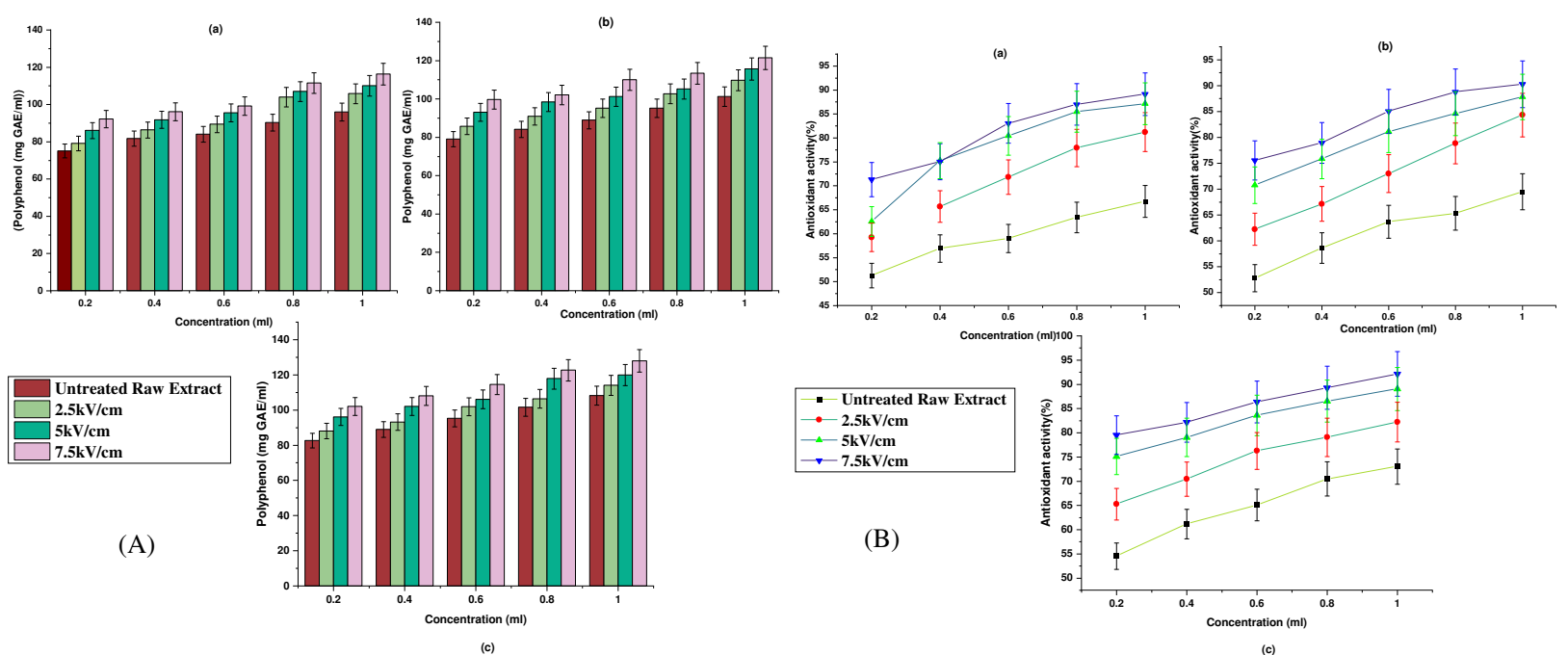

Fig. 6(A) Effect of pulsed electric field on phenolic activity of ((a) $99 \%+1 \%$ (b) $98 \%+2 \%$ and (c) $97 \%+3 \%)$ pepper + Vinca rosea combination extracts. Fig. 6(B). Effect of pulsed electric field on antioxidant activity of ((a) $99 \%+1 \%(b) 98 \%+2 \%$ and (c) $97 \%+3 \%)$ pepper + turmeric combination extracts

When mixed with neem extract and Vinca rosea extracts, a similar trend is followed as observed in Figure.7. The highest antioxidant activity of $91.77 \%$ is observed for PEF treated extracts which are $90.82 \%$ higher than untreated extracts $(42.24 \%)$ for pepper + neem combinations.
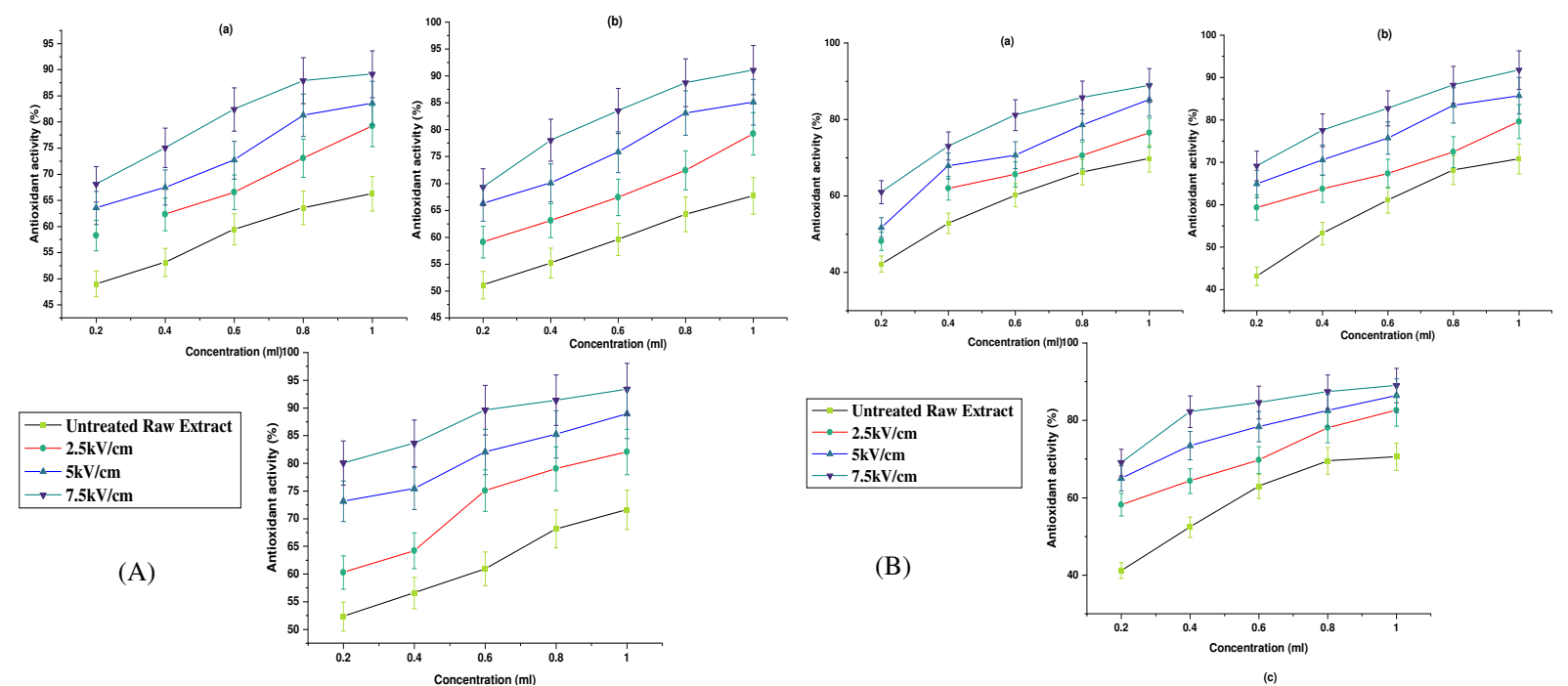

Fig. 7(A) Effect of pulsed electric field on antioxidant activity of ((a) $99 \%+1 \%$ (b) $98 \%+2 \%$ and (c) $97 \%+3 \%$ ) pepper + neem combination extracts Fig.7(B). Effect of pulsed electric field on antioxidant activity of ((a) $99 \%+1 \%$ (b) $98 \%+2 \%$ and (c) $97 \%+3 \%$ ) pepper + Vinca rosea combination extracts

\section{- Neem and its Combination}

From the literature, it is found that the combination of neem and turmeric enlarges the cellular structure of the body which allows energy to enter and fill up every crevice [21]. Hence an attempt is made to obtain the effective activity of combination extracts. Ethanolic neem extracts are combined with turmeric, pepper and Vinca rosea extracts in different proportions of $1 \%, 2 \%$ and $3 \%$ for five different concentrations. The combined effect of neem and pepper exhibits the highest phenol contents of 105.03 $\mathrm{mg} \mathrm{GAE} / \mathrm{ml}$ and the lowest phenols of $98.17 \mathrm{mg} \mathrm{GAE} / \mathrm{ml}$ for neem and turmeric combination. When these samples are subjected to electric fields, phenol contents increase with increasing concentration and fields. For certain samples, there is a slight percentage reduction in their activity, and hence further percentage addition is not done. The effect of PEF on phenol contents and antioxidant activity of neem and its combination extracts are illustrated in Figure. 8, 9 and 10. 




Fig. 8 (A) Effect of pulsed electric field on phenolic activity of ((a) 99\% + 1\% (b) $98 \%+2 \%$ and (c) $97 \%+3 \%)$ neem + Vinca rosea combination extracts. Fig. 8 (B) Effect of pulsed electric field on phenolic activity of ((a) $99 \%+1 \%$ (b) $98 \%+2 \%$ and (c) $97 \%+3 \%$ ) neem + pepper combination extracts

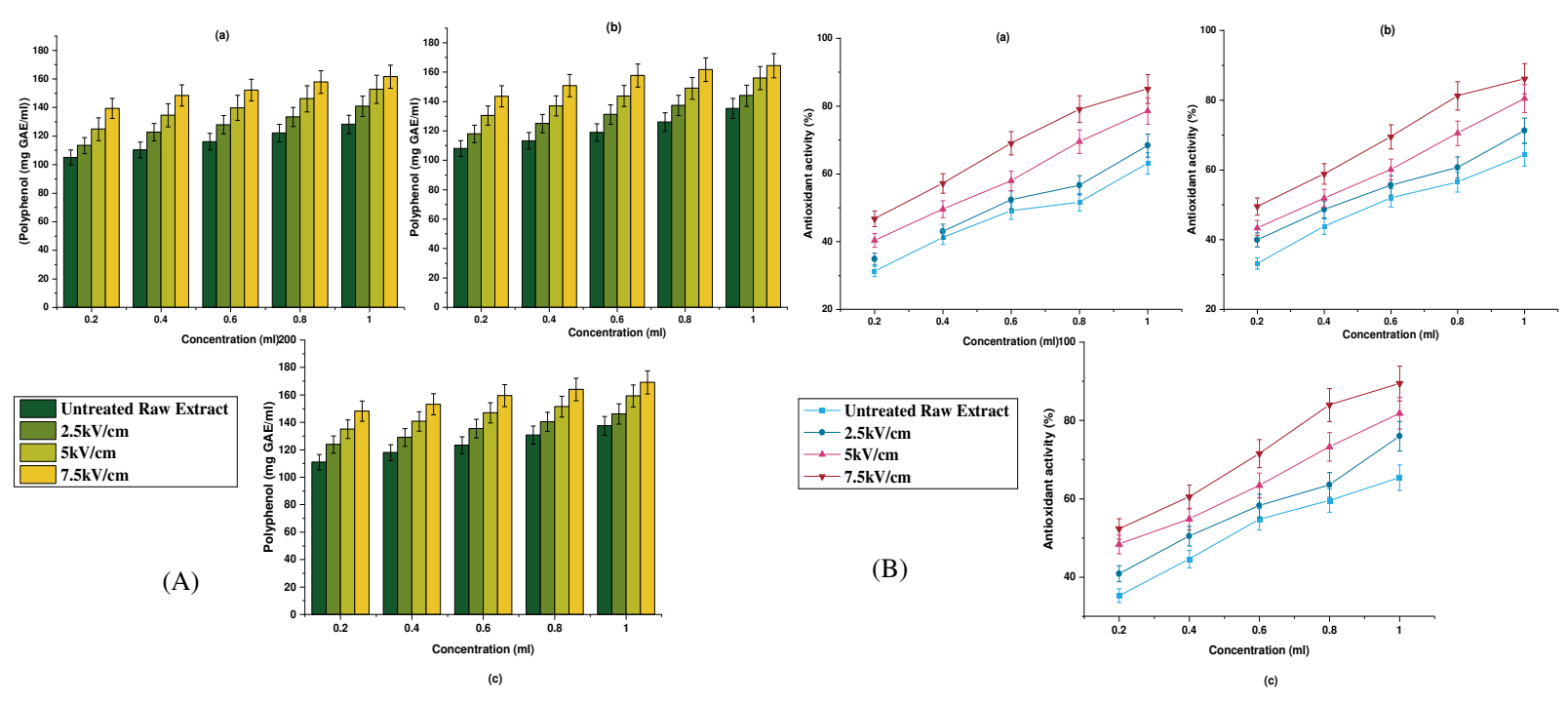

Fig. 9 (A) Effect of pulsed electric field on phenolic activity of ((a) $99 \%+1 \%$ (b) $98 \%+2 \%$ and (c) $97 \%+3 \%)$ neem + pepper combination extracts. Fig. 9 (B) Effect of pulsed electric field on antioxidant activity of ((a) $99 \%+1 \%$ (b) $98 \%+2 \%$ and (c) $97 \%+3 \%$ ) neem + turmeric combination extracts
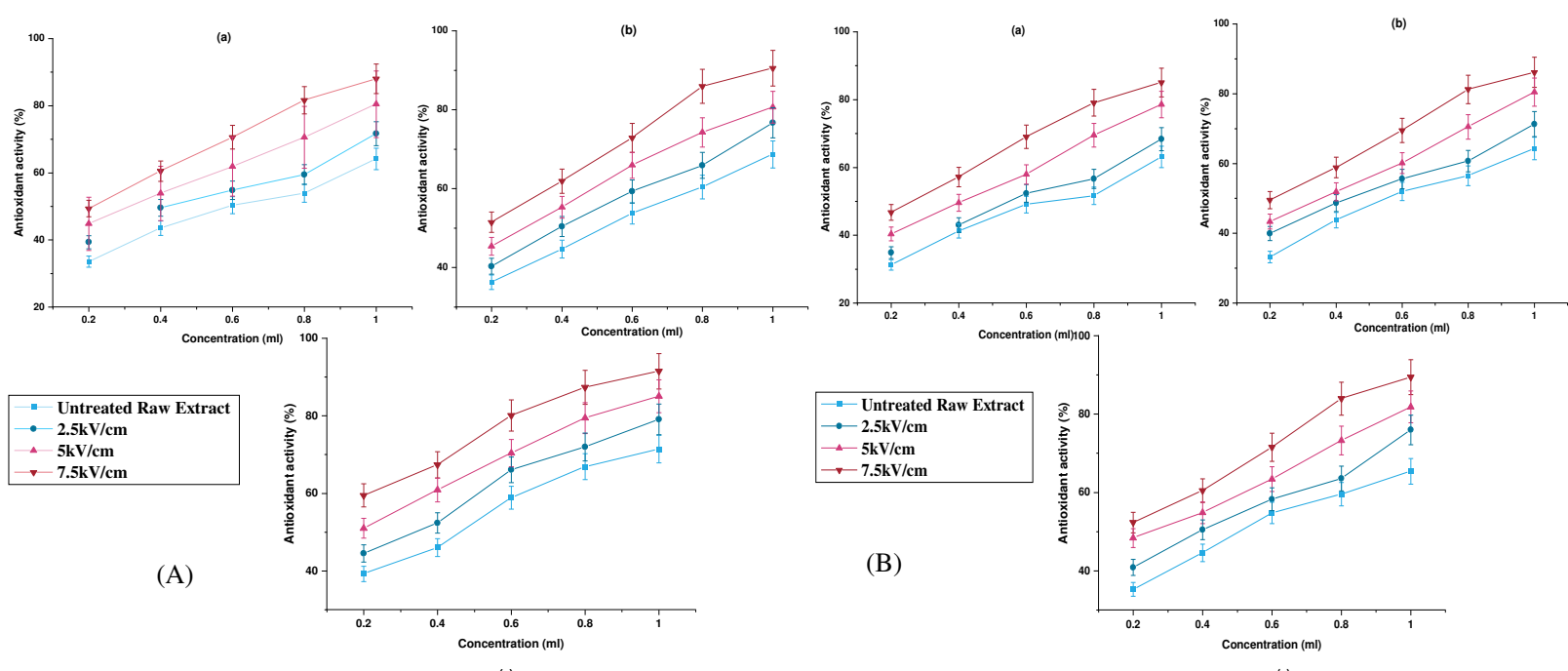

Fig. 10 (A) Effect of pulsed electric field on phenolic activity of ((a) $99 \%+1 \%$ (b) $98 \%+2 \%$ and (c) $97 \%+3 \%)$ neem + pepper combination extracts. Fig. 10 (B) Effect of pulsed electric field on antioxidant activity of ((a) $99 \%+1 \%($ b) $98 \%+2 \%$ and (c) $97 \%+$ $3 \%$ ) neem + turmeric combination extracts 
Out of all the combinations, neem mixed with pepper exhibits the highest antioxidant activity followed by (neem+turmeric) and by (neem+Vinca rosea). Similar to other works, increasing concentrations and applied electric fields increase the antioxidant activity.

\section{- Vinca rosea and its combination}

In Ayurveda, single or multiple herbs (poly-herbal) are used for the treatment. Vinca rosea is well known for its medicinal properties [7, 22]. Here, it is mixed with other extracts, to achieve higher efficiency. Vinca rosea is mixed in different proportions with other extracts, similar to the previous mixtures and their phenol contents and antioxidant activity are assessed as depicted in Figure. 11, 12 and 13. The highest phenol content of $129.41 \mathrm{mg} \mathrm{GAE} / \mathrm{ml}$ for PEF treated extracts is observed, which is a $92.1 \%$ increase when compared to untreated extracts (67.36). As the concentration of extracts increases from $0.2 \mathrm{ml}$ to $1 \mathrm{ml}$, total phenol contents and antioxidant activity increases for all treatments.


Fig. 11 (A) Effect of pulsed electric field on phenolic activity of ((a) $99 \%+1 \%$ (b) $98 \%+2 \%$ and (c) $97 \%+3 \%$ ) Vinca rosea + turmeric combination extracts Fig. 11 (B) Effect of pulsed electric field on phenolic activity of ((a) $99 \%+1 \%$ (b) $98 \%+2 \%$ and (c) $97 \%+3 \%$ ) Vinca rosea+ neem combination extracts



Fig. 12 (A) Effect of pulsed electric field on phenolic activity of ((a) $99 \%+1 \%$ (b) $98 \%+2 \%$ and (c) $97 \%+3 \%)$ Vinca rosea + pepper combination extracts. Fig. 12 (B) Effect of pulsed electric field on antioxidant activity of ((a) $99 \%+1 \%$ (b) $98 \%+2 \%$ and (c) $97 \%+$ $3 \%$ ) Vinca rosea + turmeric combination extracts

When Vinca rosea extracts are mixed with pepper extracts and subjected to varying electric fields, the highest total phenol contents of $129.41 \mathrm{mg} / \mathrm{GAEml}(7.5 \mathrm{kV} / \mathrm{cm})$ is observed as in Figure. 12(A). Similarly, when mixed with neem and turmeric, it exhibits the highest phenol contents of 126.67 for 
$7.5 \mathrm{kV} / \mathrm{cm}$ treated extracts, which is higher than untreated extracts. Interestingly, higher phenol contents are observed for $1 \%$ combination of extracts than other combinations. Phenol contents have decreased by $6.36 \%$ between $2 \%$ and $3 \%$ combinations.

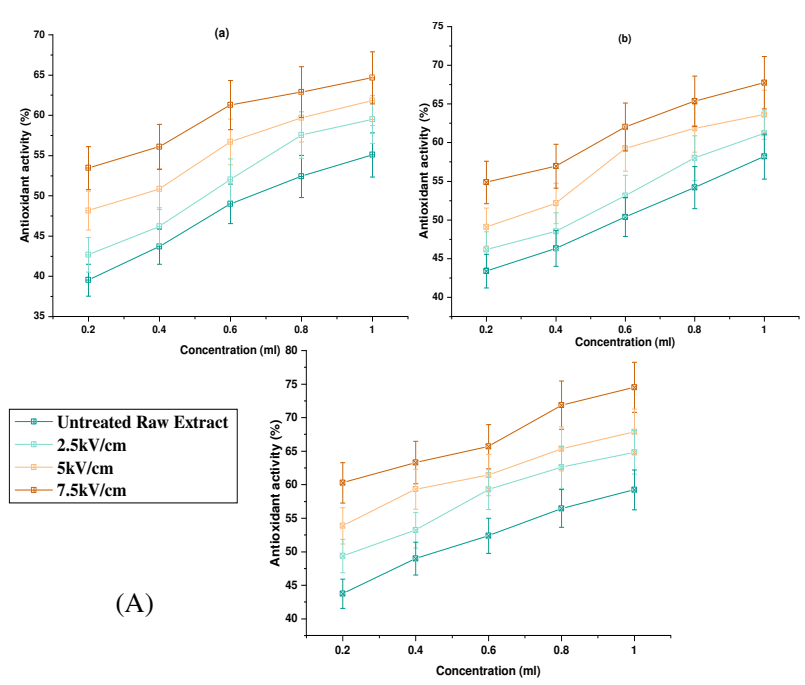

(c)

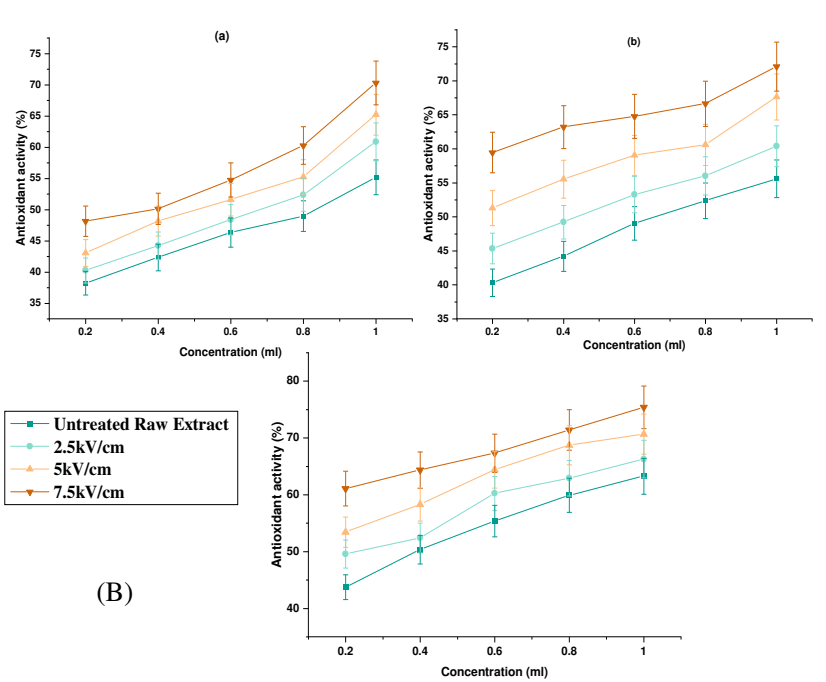

(c)

Fig. 13 (A) Effect of pulsed electric field on antioxidant activity of ((a) $99 \%+1 \%$ (b) $98 \%+2 \%$ and (c) $97 \%+3 \%$ Vinca rosea + neem combination extracts. Fig. 13 (B) Effect of pulsed electric field on antioxidant activity of ((a) $99 \%+1 \%(b) 98 \%+2 \%$ and (c) $97 \%+$ $3 \%$ ) Vinca rosea + pepper combination extracts

In our previous works $[15-17,23]$, we have analyzed the phenol contents and antioxidant activity of individual extracts, when compared with them, the obtained poly-herbal mixtures have exhibited higher phenols and antioxidant activity than individual extracts, which may be due to the synergistic effect of both the extracts. Turmeric and its combinations (turmeric with pepper) have exhibited the highest phenol content and antioxidant activity than other combinations. This might be due to the effect of pepper, as it is naturally a bio-enhancer which would have enhanced the activity of turmeric significantly [19]. Further, when these mixtures are subjected to pulsed electric fields, we could observe an increase of 20 to $50 \%$ in phenol contents and antioxidant activity of poly-herbal mixtures. Also we could observe that when the concentration of the extracts increases from 0.2 to $1 \mathrm{ml}$, both phenol contents and antioxidant activity increases $(1>0.8>0.6>0.4>0.2 \mathrm{ml})$ and also for higher electric fields $(7.5>5>2.5 \mathrm{kV} / \mathrm{cm})$, activity increases. The increase in total phenolic content and antioxidant activity detected in this study is comparable to our previous studies as PEF improves the phenolic contents and antioxidant activity [1517, 23, 24]. Luengo et al. 2013 [25] have used electrical pulses to extract the polyphenols and flavonoids from orange peels under $1,3,5$ and $7 \mathrm{kV} / \mathrm{cm}$. They have reported $20 \%, 129 \%, 153 \%$, and $159 \%$, increase in phenol contents. This shows a good correlation with higher phenol contents for PEF treated extracts in this study, as the phenol contents increase for increasing applied electrical fields and increasing concentrations.

PEF-treated extracts show more antioxidant activity than the untreated extract; this increased pattern might be due to increased permeability of plant cells resulting in higher extractability and enhanced mass transfer of intracellular metabolite extraction. Further, the antioxidant activity is proportional to the total phenol contents for all treatments. The higher the content of phenol compounds in PEF treated extracts can be probably related to the higher antioxidant activity observed, in agreement with previous literature. Poly-herbal mixtures (Turmeric with pepper) that possess more antioxidant activity and phenol contents are chosen as a drug to treat breast cancer cell lines.

\section{Cytotoxic activity:}

Turmeric, a golden Indian spice is very well known for its medicinal properties. Similarly, black pepper is another common spice offering multiple health benefits. When both are combined together, they tend to have a greater effect on inflammation, digestion, reducing pain and fighting cancer. Curcumin is the 
key compound of turmeric and on the other hand, piperine is present in black pepper. Piperine aids in better absorption of curcumin [26]. Hence, this powerful combination of turmeric and pepper extracts is experimented on MCF-7 cells. Interestingly, this combination possesses more antioxidant and phenol contents than other extracts and their combinations. Further, the synergy of electrical pulses and the polyherbal extracts is also explored. Pulsed poly-herbal extracts $(7.5 \mathrm{kV} / \mathrm{cm}, 100 \mu \mathrm{s}, 99$ pulses) which exhibited higher phenol contents and antioxidant activity is used.

\section{- $\quad$ Turmeric (99\%) with pepper (1\%)}

The cytotoxic activity of combined (Turmeric (99\%) with pepper (1\%)) extracts and electrical pulses on MCF-7 breast cancer cell lines has been investigated. Figure 14 presents the cell survival values under different treatment conditions for eight different concentrations: Raw extract only, pulsed extract, pulsed extract + EP1, pulsed extract + EP2. Cell death caused by raw extract only $(7.8 \mu \mathrm{g} / \mathrm{ml})$ is $10.2 \%, 18.31 \%$ and $24.48 \%$ at $24 \mathrm{~h}, 48 \mathrm{~h}$, and $72 \mathrm{~h}$ respectively. For the highest concentration of $1000 \mu \mathrm{g} / \mathrm{ml}$, cell death observed is about $66.92 \%, 70.16 \%$ and $68.23 \%$ after $24 \mathrm{~h}, 48 \mathrm{~h}$, and $72 \mathrm{~h}$ respectively. Cell viability decreases for increasing concentrations for all treatments. When cells are treated with pulsed extract only, cell death of $70.23 \%, 71.22 \%$ and $79.35 \%$ after $24 \mathrm{~h}, 48 \mathrm{~h}$ and $72 \mathrm{~h}$ is observed. Further, the synergy of electrical pulses and pulsed extracts has been experimented. When high-intensity low duration electrical pulses (EP1) are used to deliver combined extract, cell death of $82.2 \%$, after $24 \mathrm{~h}, 80.1 \%$ after $48 \mathrm{~h}$ and $84.52 \%$ after $72 \mathrm{~h}$ have been observed respectively. Low-intensity high duration (EP2) with combined extracts yield cell kill of $89 \%, 90.5 \%$, and $92.1 \%$ after $24 \mathrm{~h}, 48 \mathrm{~h}$, and $72 \mathrm{~h}$ of treatment. On comparing the cell death caused by different treatments, (EP2, low-intensity high duration) treatment yielded the highest cell kill of about $92.1 \%$ after $72 \mathrm{~h}$. This goes well with the observed microscopic images as in Figure. 15.
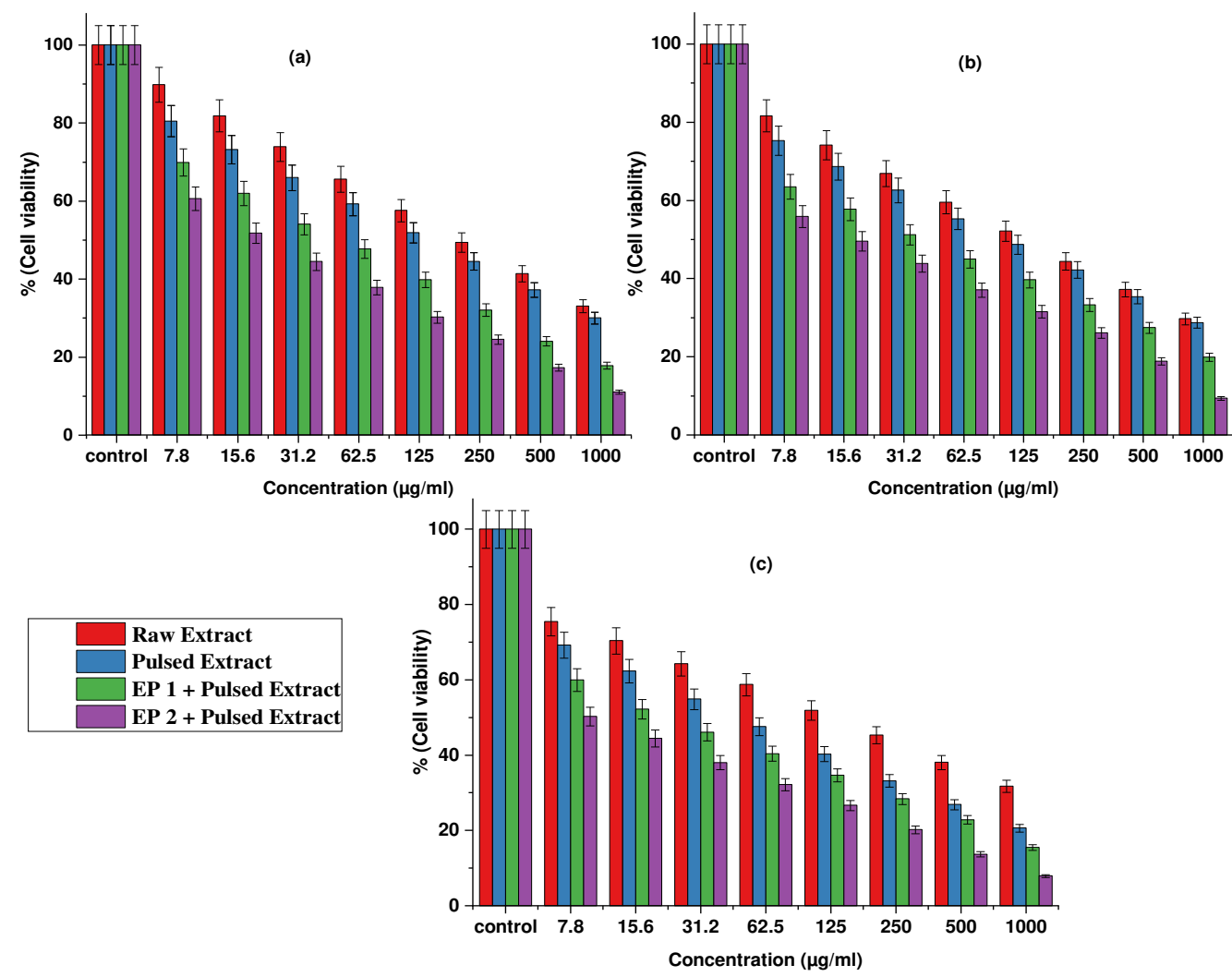

Fig. 14 Viabilities of MCF-7 after (a) $24 \mathrm{hrs}$ (b) $48 \mathrm{hrs}$ (c) $72 \mathrm{hrs}$ when treated with raw extracts, pulsed extracts and combined treatment of turmeric $(99 \%)$ and pepper (1\%)extracts and electrical pulses. The results are based on the experiment performed in triplicate. Error bars are calculated using standard error.

Synergetic treatment exhibits the lowest half-maximal inhibitory concentration (IC50) of $15.6 \mu \mathrm{g} / \mathrm{mL}$, whereas the raw extracts exhibit an IC50 value of $500 \mu \mathrm{g} / \mathrm{mL}$ which dropped to $125 \mu \mathrm{g} / \mathrm{mL}$ for pulsed extracts and further dropped down to $31.2 \mu \mathrm{g} / \mathrm{mL}$ for EP1 combined treatment after 24 hours. Hence, there 
is about $\sim 97 \%$ decrease in IC50 value indicating that electrical pulses reduce the inhibitory concentration of extract required in treating MCF-7 cells. After $72 \mathrm{~h}$, the IC50 value for raw extract is $125 \mu \mathrm{g} / \mathrm{mL}$, for pulsed extract it is $62.5 \mu \mathrm{g} / \mathrm{mL}$ and for combined treatment it is $15.6 \mu \mathrm{g} / \mathrm{mL}$ and $7.8 \mu \mathrm{g} / \mathrm{mL}$ respectively. A similar trend is followed for all the treatments. This clearly indicates that the electrical pulse reduces the inhibitory concentration of extracts required to treat cell lines.

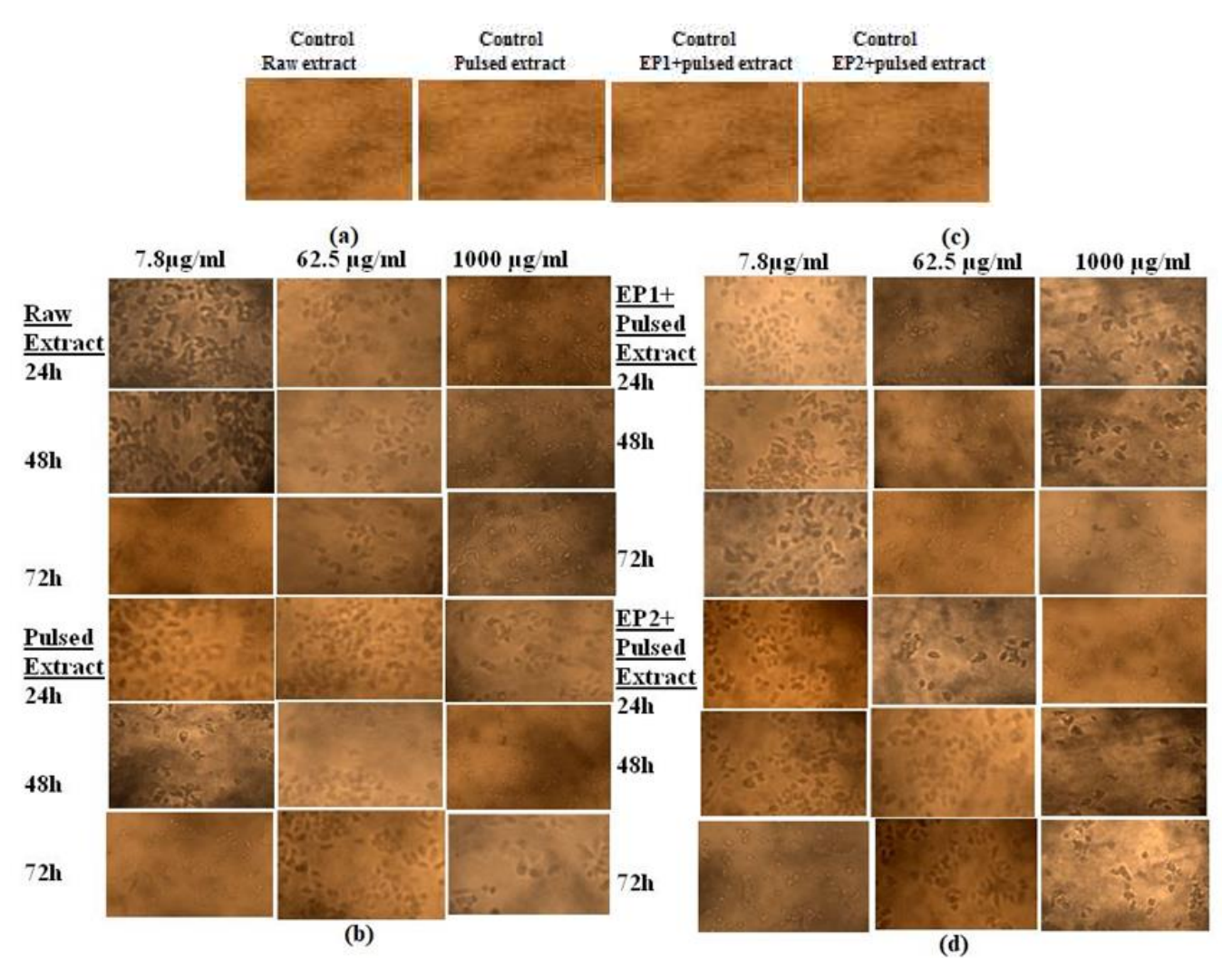

Fig. 15 Typical microscopic images of MCF-7 cells after 24, 48, and 72 hours for combined treatment of turmeric (99\%) and pepper (1\%)extracts: (a) without any treatment (raw extract), (b) with pulsed extract alone, combination effect of pulsed extract and electrical pulses ((c) EP 1 \& (d) EP2).

\section{- Turmeric (98\%) with Pepper (2\%)}

Similarly, when $98 \%$ of turmeric extracts are mixed with $2 \%$ of pepper extracts and experimented with, cell viabilities are quite lesser than the previous combination treatment. Cell death of $72.04 \%$ was observed for raw extract, $78.53 \%$ for pulsed extract, followed by $89.86 \%$ for EP1+ pulsed extract and $91.54 \%$ for EP2 + pulsed extracts after $24 \mathrm{~h}$ of treatment for $1000 \mu \mathrm{g} / \mathrm{ml}$. A similar trend has been observed for $48 \mathrm{~h}$ and $72 \mathrm{~h}$ of treatment. When compared to all treatments, low-intensity high duration electrical pulses with combined extracts yield more cell kill. Cell death increases with increasing concentrations of extracts in all treatments. The highest cell death of $98.33 \%$ is achieved for EP2 + extract treatment after 72 hours of treatment, which shows the lasting effect of the treatment. Electric pulse mediated therapy on human breast cancer cell lines show better results by killing more cells. The IC50 value for raw extract alone is found to be $125 \mu \mathrm{g} / \mathrm{ml}$, and for pulsed extract, it is about $31.2 \mu \mathrm{g} / \mathrm{ml}$, $15.6 \mu \mathrm{g} / \mathrm{ml}$ for EP1+Pulsed extract and $7.8 \mu \mathrm{g} / \mathrm{ml}$ for EP2+Pulsed extract after $24 \mathrm{~h}$. The concentration of Pulse treated extract required to treat MCF-7 cells is less when compared to the concentration of untreated raw extracts. This clearly points out the potential of combination therapy on breast cancer cell lines. Electrical pulses have been used to deliver chemo drugs in previous literature, which annihilated more cancer cells than chemo drugs alone. The statistical significance test is done to check whether the values obtained are significantly different from each other $(\mathrm{P}<0.05)$. All the treatments except control samples are found to be different from each other indicating all the viabilities are statistically different from each other. 

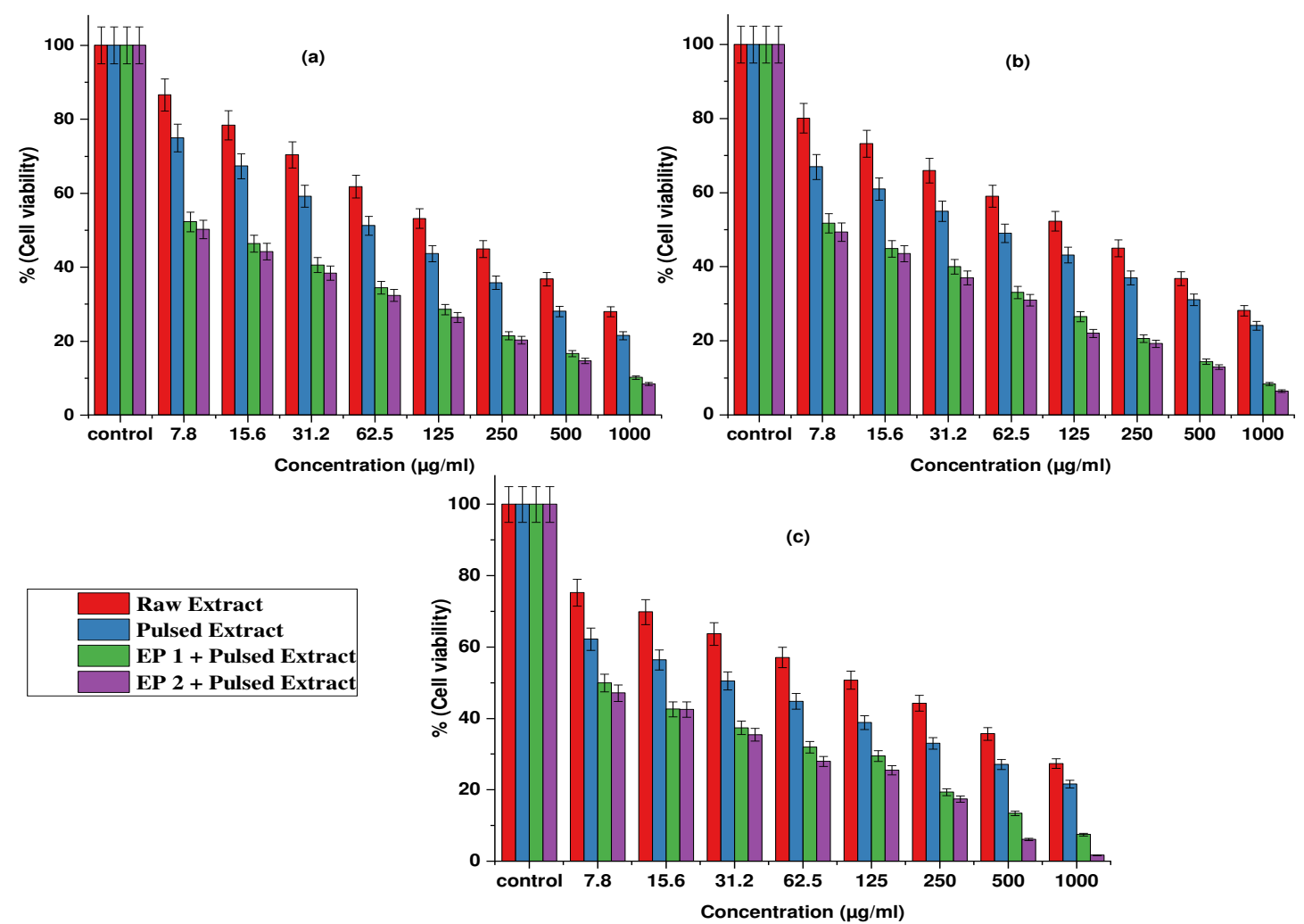

Fig. 16 Viabilities of MCF-7 after (a) $24 \mathrm{hrs} \mathrm{(b)} 48 \mathrm{hrs}$ (c) $72 \mathrm{hrs}$ when treated with raw extracts, pulsed extracts and combined treatment of turmeric $(\mathbf{9 8 \%})$ and pepper (2\%) extracts and electrical pulses.

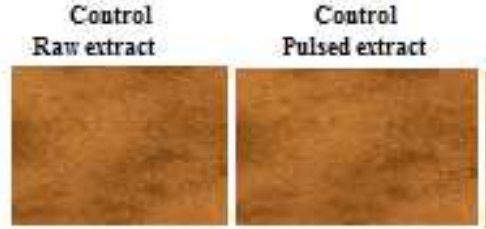

(a)

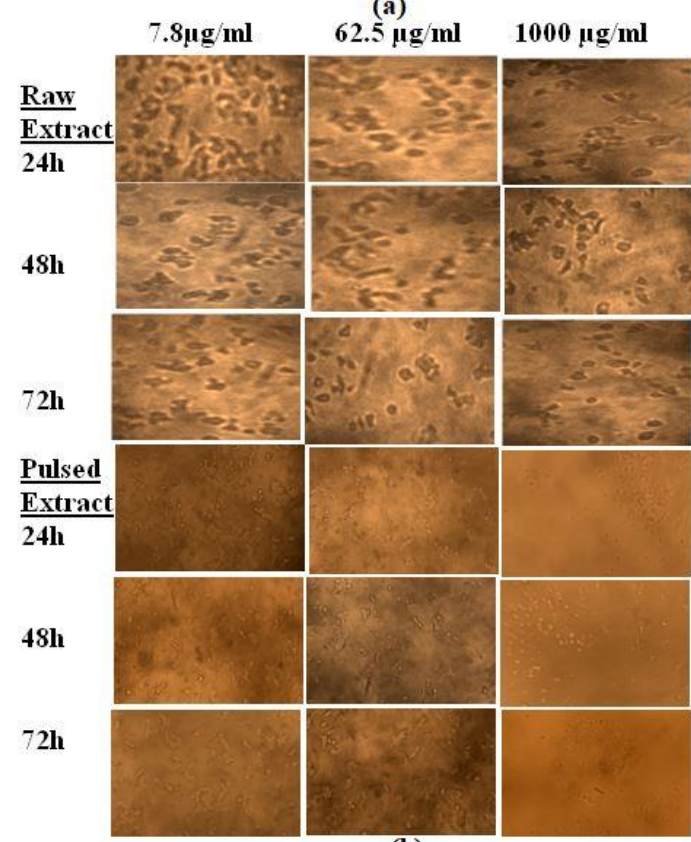

(b)

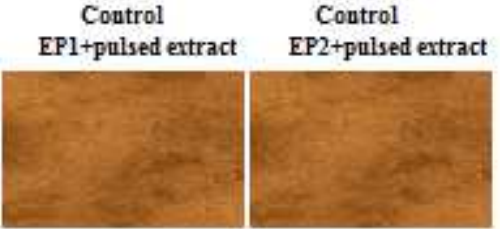

(c)

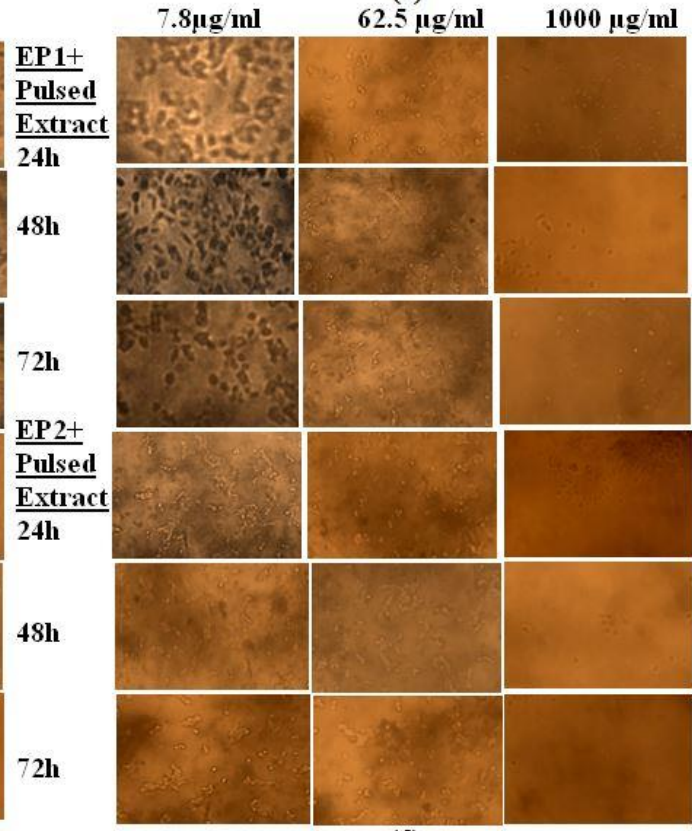

(d)

Fig. 17 Typical microscopic images of MCF-7 cells after 24, 48, and 72 hours for combined treatment of turmeric (98\%) and pepper (2\%)extracts: (a) without any treatment (raw extract), (b) with pulsed extract alone, combination effect of pulsed extract and electrical pulses ((c) EP 1 \& (d) EP2) 
When the treatment is repeated for other concentrations, from $7.8 \mu \mathrm{g} / \mathrm{ml}$ to $1000 \mu \mathrm{g} / \mathrm{ml}$, the cell survival rates are less when compared to the lowest concentration. An increase in the duration of electric pulses from microseconds to milliseconds has led to a greater cytotoxic effect as observed from Figure. 16. Typical microscopic images of MCF-7 cells after 24, 48 and 72 hours of treatment are illustrated in Figure. 17. When treated with raw extracts (Figure. 17(a)), cell confluence reduces with time. Further, when treated with the pulsed extract (Figure. 17(b)), the cells form clusters which may be due to the alterations in the cell. In the cells treated with $1200 \mathrm{~V} / \mathrm{cm}, 100 \mu \mathrm{s}$, 8pulses (Figure. 17(c)), cells tend to lose their adhesive properties, unlike other treatments. This indicates the differential mechanism when MCF-7 cells are treated with a combination of extracts and electrical pulses. Microscopic pictures obtained under low intensity, high duration electrical pulses $(500 \mathrm{~V} / \mathrm{cm}, 20 \mathrm{~ms}, 8$ pulses) (Figure. 17(d)), indicate the absence of live cells after 24,48 and $72 \mathrm{~h}$ of treatment. This goes well with the viability count obtained in the MTT assay (Figure. 16).

\section{- Turmeric (97\%) with Pepper (3\%)}

Figure. 18 illustrates the viabilities at the various conditions, including, raw extract only, pulsed extract only and the two conditions of combined extract (Turmeric (97\%) with pepper (3\%)) and electroporation. Cell viabilities are measured after 24, 48 and 72 hours of treatment. When low intensity, high duration electrical pulses $(500 \mathrm{~V} / \mathrm{cm}, 20 \mathrm{~ms}, 8$ pulses $)$ are used to deliver the extracts, it yielded cell viability of $\sim 12 \%$, and $\sim 15 \%$ with high intensity, low duration pulses of $1200 \mathrm{~V} / \mathrm{cm}, 100 \mu \mathrm{s}, 8$ pulses and $\sim 16 \%$ with pulsed extract only and $\sim 23 \%$ with raw extract only after 24 hours. After 48 hours of treatment, cell viabilities have been reduced for all treatments. After 72 hours of treatment, $7 \%$ viability is obtained with $500 \mathrm{~V} / \mathrm{cm}, 20 \mathrm{~ms}, 8$ pulses and $\sim 10 \%$ viability is obtained with $1200 \mathrm{~V} / \mathrm{cm}, 100 \mu \mathrm{s}$, and 8 pulses treatment. Viabilities observed are $\sim 1.5$ times lower compared to EP1 treatment and $\sim 5.5$ times lower than pulsed extract only and $\sim 6.5$ times lower than raw extract only treatment. These reductions in the cell viability after $72 \mathrm{~h}$ of treatment indicate the long-term efficacy of the extract against MCF-7.

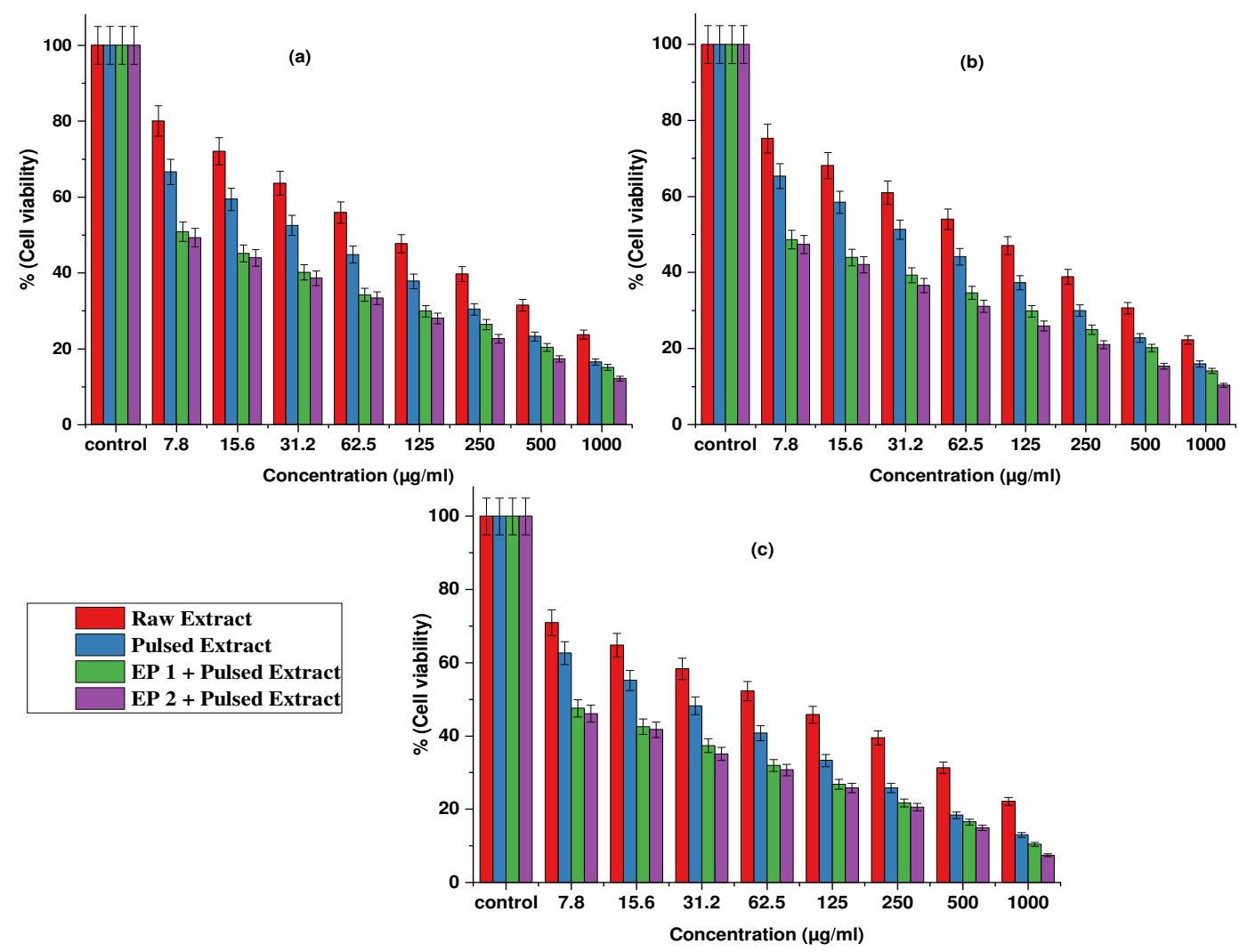

Fig. 18 Viabilities of MCF-7 after (a) 24hrs (b) $48 \mathrm{hrs}$ (c) $72 \mathrm{hrs}$ when treated with raw extracts, pulsed extracts and combined treatment of turmeric $(97 \%)$ and pepper (3\%)extracts and electrical pulses. 
With obtained results, it can be said that low-intensity high duration electrical pulses were found more effective in combination with extracts (turmeric (97\%) + pepper (3\%)) than other treatments. When delivered using electrical pulses, they would have offered high permeability for the extracts to enter the MCF-7 cells easily. This offers high cell death in the combined treatment of EP and extracts. Cell viability results indicate that the presence of electrical pulses with extracts significantly reduced the viability in a concentration-dependent manner, compared to the control and raw extract-only treatments. Cell death percentage increases with increasing time and concentrations. This is obvious as the MCF-7 cells were exposed to electrical pulses for a longer time with more concentration of anticancer extracts might have caused higher cell death. The maximal inhibitory concentration (IC50) value for raw extracts is $62.5 \mu \mathrm{g} / \mathrm{ml}, 31.2 \mu \mathrm{g} / \mathrm{ml}$ for pulsed extracts and it has dropped to $15.6 \mu \mathrm{g} / \mathrm{ml}$ and $7.8 \mu \mathrm{g} / \mathrm{ml}$ for synergetic treatments. After $72 \mathrm{~h}$ of treatment, the IC50 value has further reduced. This indicates that the electrical pulses reduce the inhibition concentration of extracts required to treat MCF-7 cell lines. When MCF-7 cell lines are exposed to electrical pulses, an increase in permeability of cell membrane would have happened which led to higher uptake of extracts into the cell and thereby reduction in the concentration of extracts required to treat cell lines is observed. Furthermore, as observed before, when time duration is increased from microseconds to milliseconds, it led to higher cytotoxicity.

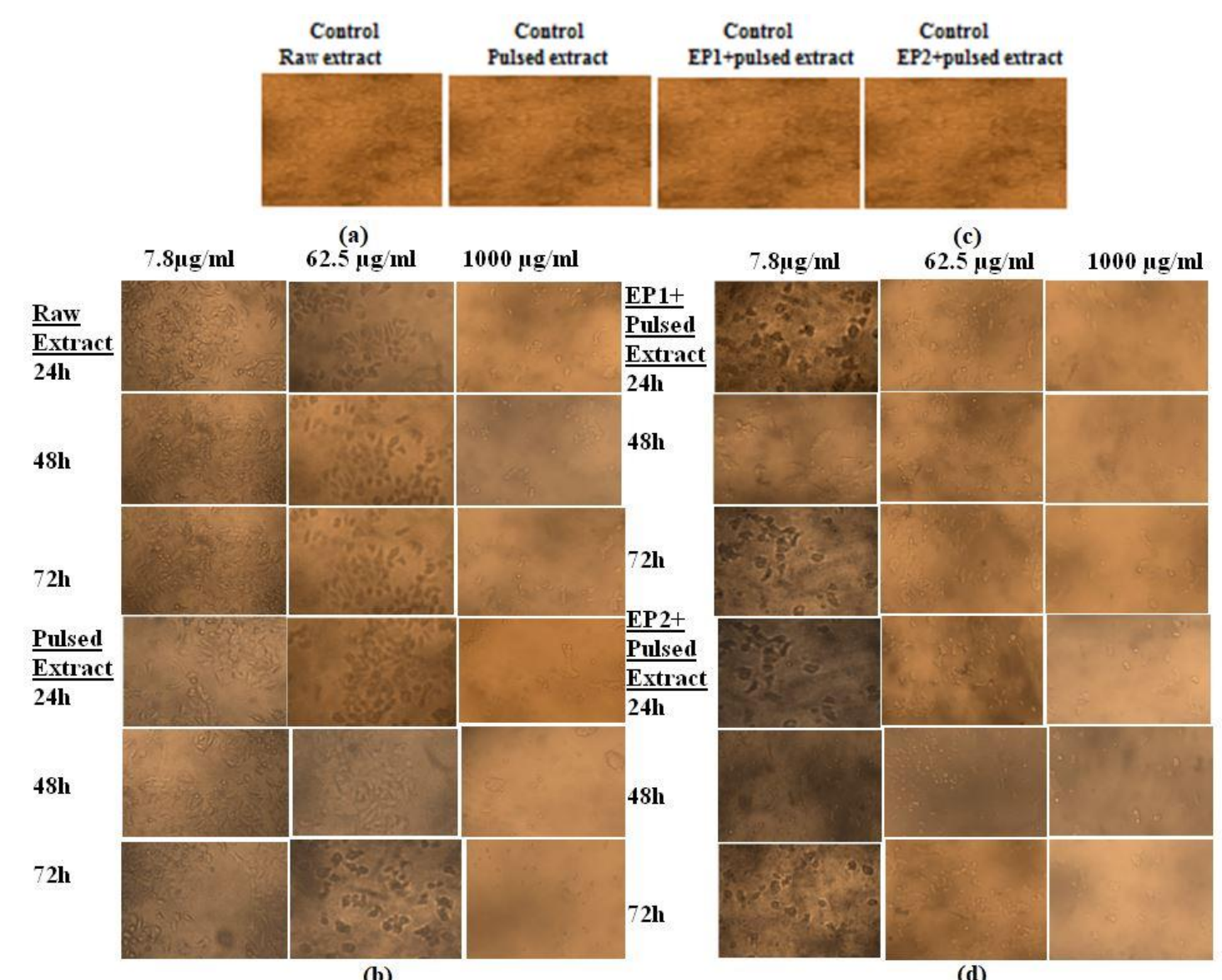

(b)

(d)

Fig. 19 Typical microscopic images of MCF-7 cells after 24, 48, and 72 hours for combined treatment of turmeric (97\%) and pepper (3\%)extracts: (a) without any treatment (raw extract), (b) with pulsed extract alone, combination effect of pulsed extract and electrical pulses ((c) EP 1 \& (d) EP2)

The statistical significance test is done to check whether the values obtained are significantly different from each other $(\mathrm{p}<0.05)$. All the treatments except control samples are found to be different from each other indicating all the viabilities are statistically different from each other. Figure. 19 shows the microscopic images of MCF-7 cells after 24, 48 and 72 hours of treatment. When MCF-7 cells are exposed to raw extract only (Figure. 19(a)), slight alterations in the cell structure have been observed. Further, when treated with pulsed extracts only (Figure. 19(b)), cells appear to lose their 
tightly packed arrangement. Furthermore, for synergetic treatment, when treated with electrical pulses and extracts (Figure. 19(c)), cells detach from each other losing their properties, as they do not form clusters. For EP2 + pulsed extract treatment (Figure. 19(d)), the microscopic pictures indicate the absence of live cells after $72 \mathrm{~h}$ of treatment. This is in agreement with the viability results obtained in the MTT assay, where $12 \%, 10 \%$ and $7 \%$ of live cells are observed after 24, 48 and 72 hours. Previously, a study conducted by Pehlivanova, et al. [27] indicates that electroporation can reduce cell adhesion and replication, which is going well with this study.

From our cytotoxicity study, it can be seen clearly that the cell lines, when treated with electrical pulses and pulsed turmeric pepper combinations, have the lowest cell viability of $1.67 \%$ are observed. Cell viabilities decrease over the time period from 24hours to 72 hours indicating the long-term efficacy of the treatments. When the cell lines are treated with raw extracts alone, the cell viability decreases, whereas when treated with pulsed extracts the cell viability decreases more than the previous treatment. Further, when mediated with electrical pulses, significant decreases in cell viabilities are observed. This indicates the efficacy of synergetic treatments. These results ascertain the results presented in the previous sections.

Anticancer drugs such as cisplatin, bleomycin, carboplatin, and doxorubicin are used to treat breast cancer depending upon the stage of cancer. Cisplatin is the most commonly administered drug to treat breast cancer and hence, the results obtained from our previous study are used to compare with the results obtained in this current study. This helps in emphasizing the efficacy of herbal extracts as an alternative chemo-drug. When MCF-7 is treated with cisplatin and electric pulses earlier, viabilities of $50.9 \%$ and $61.8 \%$ for $125 \mu \mathrm{g} / \mathrm{ml}$ and $62.5 \mu \mathrm{g} / \mathrm{ml}$ concentrations of cisplatin only are observed. Further, when mediated with electrical pulses, the viability had reduced to $45.4 \%$ and $50.4 \%$ [28]. In contrast, when herbal extracts are used to treat MCF-7 cells, the lowest viability of $45.44 \%$ for $125 \mu \mathrm{g} / \mathrm{ml}$ concentration is observed, whereas, for pulsed extracts, a decrease of $55.59 \%$ is observed. In addition, when electrical pulses are used to enhance the uptake of extracts, the cell viability further reduces. On comparing the viabilities with cisplatin treatment, a decrease of $96.72 \%$ is noticed in cell viabilities when treated with synergetic treatments. Hence, the results obtained from this study with viabilities as low as $1.67 \%$, indicate that the electrical pulse mediated phytomedicines can be used instead of synthetic drugs, thereby increasing the quality of life in the

\section{Conclusions:}

In summary, we demonstrate experimentally that the application of pulsed electric field efficiently contributes to enhanced extraction of phytochemicals from poly-herbal extracts and improved cytotoxic activity against MCF-7 breast cancer cells. Our work supports that the combined extracts are more preferable to single extracts, due to their increased bioactivity, which might be due to the additive or synergistic effect of the bioactive compounds present in both extracts. The major challenge of lower bioavailability of herbal extracts or formulations can be overcome by using the PEF technique. Hence, phenolic-rich and antioxidant-rich extracts have been achieved, which could be a potent source to treat various diseases. Higher antioxidant activity and phenol contents of PEF treated extracts can be correlated to a higher cytotoxic activity against breast cancer cells than untreated extracts. Hence combined treatment of PEF and poly-mixture extracts can be opted as a better option against breast cancer cells. Desired cell death can be achieved by optimizing the electrical pulse parameters. The drug dosage required to cause substantial damage to the cancer cells can be reduced by using this technique. With expensive treatments available conventionally, this treatment might be extended to clinical settings, as poly-herbal mixtures with electrical pulses are as effective as conventional drugs. This might alleviate the negative impacts of conventional chemical drugs and therapies, thus enhancing the quality of life in affected patients. 


\section{Authors Contributions}

Concept and design: Gowri Sree V

Sample collection and extract preparation: Poompavai S

Viability and other Experiments: Poompavai $S$

Data Analysis: Gowri Sree V, Poompavai S

Manuscript: Gowri Sree V, Poompavai S

\section{Availability of data and materials}

All data sources could be available to readers on request.

\section{Ethical approval and consent to participate}

Not applicable

\section{Funding Information}

This work was supported by Anna University under Anna Centenary Research Fellowship Award.

\section{Compliance with Ethical Standards}

Conflict of Interest: The authors declare that they have no competing interests.

\section{References:}

1. Diana, I, Santos, Jorge Manuel Alexandre Saraiva, António, A, Vicente, Margarida Moldão-Martins (2019). Methods for determining bioavailability and bioaccessibility of bioactive compounds and nutrients. Innovative Thermal and Non-Thermal Processing, Bioaccessibility and Bioavailability of Nutrients and Bioactive Compounds, Woodhead Publishing Series in Food Science, Technology and Nutrition, pp. 23-54.

2. Javed Iqbal, Banzeer Ahsan, Abbasi, Tariq Mahmood, Sobia Kanwal, Barkat Ali, Sayed Afzal Shah \& Ali Talha Khalil (2017). Plant-derived anticancer agents: A green anticancer approach. Asian Pacific Journal of Tropical Biomedicine. Vol. 7, no. 12, pp. 1129-1150.

3. Si-Yuan Pan, Gerhard Litscher, Si-Hua Gao, Shu-Feng Zhou, Zhi-Ling Yu, Hou-Qi Chen, Shuo-Feng Zhang, Min-Ke Tang, Jian-Ning Sun,1 and Kam-Ming Ko. (2014). Historical Perspective of Traditional Indigenous Medical Practices: The Current Renaissance and Conservation of Herbal Resources. Evidence-Based Complementary and Alternative Medicine, Vol 2014, Article ID 525340, 20 pages. http://dx.doi.org/10.1155/2014/525340

4. Dias, D. A., Urban, S., \& Roessner, U. (2012). A historical overview of natural products in drug discovery. Metabolites, 2(2), 303-336. https://doi.org/10.3390/metabo2020303

5. Akshada Amit Koparde, Rajendra Chandrashekar Doijad and Chandrakant Shripal Magdum. (Natural Products in Drug Discovery. Pharmacognosy - Medicinal Plants. http://dx.doi.org/10.5772/ intechopen.82860.

6. Ayse Tulin Oz and Ebru Kafkas (March 1st 2017). Phytochemicals in Fruits and Vegetables, Superfood and Functional Food - An Overview of Their Processing and Utilization, Viduranga Waisundara and Naofumi Shiomi, IntechOpen, DOI: 10.5772/66987. Available from: https://www.intechopen.com/chapters/53698

7. Parasuraman, S., Thing, G. S., \& Dhanaraj, S. A. (2014). Polyherbal formulation: $\begin{array}{llll}\text { Concept of } & \text { ayurveda. Pharmacognosy } 80 .\end{array}$ https://doi.org/10.4103/0973-7847.134229

8. Karole S, Shrivastava S, Thomas S, Soni B, Khan S, Dubey J, Dubey SP, Khan N, Jain DK. (2019). Polyherbal Formulation Concept for Synergic Action: A Review. JDDT, 15 
Feb.

2019,9(1-s):453-66.

Available

from:

http://jddtonline.info/index.php/jddt/article/view/2339

9. Kumar, K., Yadav, A.N., Kumar, V. et al. (2017). Food waste: a potential bioresource for extraction of nutraceuticals and bioactive compounds. Bioresour. Bioprocess. 4, 18. https://doi.org/10.1186/s40643-017-0148-6

10. Nowosad, K, Sujka, M, Pankiewicz, U, Radosław Kowalski. (2021). The application of PEF technology in food processing and human nutrition. Journal of Food Science and Technology, Vol.58, pp. 397-411. https://doi.org/10.1007/s13197-020-04512-4

11. Johan Lindmark, Anders Lagerkvist, Erik Nilsson, My Carlsson, Eva Thorin \& Erik Dahlquist,. (2014). Evaluating the Effects of Electroporation Pre-treatment on the Biogas Yield from Ley Crop Silage. Appl Biochem Biotechnology.174:2616-2625, DOI 10.1007/s12010-014-1213-7

12. Valentina Ganeva \& Bojidar Galutzov \& Justin Teissie. (2014). Evidence that Pulsed Electric Field Treatment Enhances the Cell Wall Porosity of Yeast Cells. Appl Biochem Biotechnology. 172:1540-1552 DOI 10.1007/s12010-013-0628-x

13. Poompavai, S, \& Gowri Sree, V. (2021). Synergy of Electrical pulses and Black pepper extracts for Effective Treatment of Breast Cancer: An in vitro Model Study, IETE Journal of Research, DOI: 10.1080/03772063.2021.1896977.

14. Jaradat, N , Hussen, F \& Al Ali, A. (2015). Preliminary phytochemical screening, quantitative estimation of total flavonoids, total phenols and antioxidant activity of Ephedra alata Decne. J. Mater. Environ. Sci., Vol. 6, no. 6, pp. 1771-8. ISSN: 20282508.

15. Poompavai Sadasivam, Gowri Sree V (2020). Anti-Proliferative Efficiency of Pulsed Electric Field Treated Curcuma Longa. (Turmeric) Extracts on Breast cancer cell lines, IETE Journal of Research (ID: 1799873, DOI:10.1080/03772063.2020.1799873).

16. S. Poompavai \& V. Gowri Sree. (2021). Synergy of Electrical Pulses and Black Pepper (Piper nigrum) Extracts for Effective Breast Cancer Treatment: An in Vitro Model Study. IETE Journal of Research, DOI: 10.1080/03772063.2021.1896977.

17. S. Poompavai \& V. Gowri Sree. (2021). Enhanced extraction and improved anticancer activity of (Azadirachta indica.) Neem leaves by electroporation technique", IETE Journal of Research (In press). https://doi.org/10.1080/03772063.2021.1962743.

18. Montgomery, D.C. Design and Analysis of Experiments, John Wiley \& Sons.A, New York, 2013.

19. Shoba, G , Joy, D , Joseph, T , Majeed, M , Rajendran, R , Srinivas, P S. (2013). Influence of piperine on the pharmacokinetics of curcumin in animals and human Volunteers. Planta Med. Vol. 64, no. 4, pp. 353-6. doi: 10.1055/s-2006-957450. PMID: 9619120

20. Kesarwani, Kritika. (2013). Bioavailability enhancers of herbal origin: an overview. Asian Pacific journal of tropical biomedicine. Vol. 3,4 ,2013, 253-66. doi:10.1016/S2221-1691(13)60060-X

21. The combined benefits of NEEM and TURMERIC, Available online: http://www.theneempeople.com

22. Padmaa Paarakh, M, Swathi, S, Tasneem Taj, Tejashwini, V \& Tejashwini, B (2019). Catharanthus roseus Linn-A Review', Acta Scientific Pharmaceutical Sciences,Vol. 3, no.10, pp. 19-24.

23. S. Poompavai, V. Gowri Sree, and R. Sundararajan. (2018). Effect of pulsed electric field on Alkaloids of Vinca rosea root. Arch. Diabetes Endocr. Syst., Vol. 1, no. 2, ISSN 2638- 4981.

24. Jeyashree Thulasidas, Gowri Sree Varadarajan, Poompavai Sadasivam, Raji Sundararajan, et.al., (2019). Inhibition of Proliferation of HeLa Cells by Pulsed Electric Field Treated Mentha piperita (Mint) Extract. IETE Journal of Research. https://doi.org/10.1080/03772063.2019.1626295. 
25. Luengo E, Álvarez I Raso J. (2013). Improving the pressing extraction of polyphenols of orange peel by pulsed electric fields. Innov. Food Sci. Emerg. Technol. 17, 79-84.

26. Kanika Sharma Sonam and Sanjay Guleria. (2017). Synergistic Antioxidant Activity of Natural Products. Annals of Pharmacology and Pharmaceutics, Vol. 2, no. 8 Article 1086.

27. Pehlivanova, VN ,Tsoneva, IH \& Tzoneva, RD (2012). Multiple effects of electroporation on the adhesive behaviour of breast cancer cells and fibroblasts', Cancer. Cell. Int., Vol. 12, no. 1, pp. 9,. DOI:10.1186/1475-2867-12-9.

28. V. Gowri Sree, C. Muthuraman, and R. Sundararajan. (2017). Electro-cisplatin-therapy for estrogen-receptor positive breast cancers: an in vitro model study. J. Cancer Prev.Curr. Res., Vol. 7, no. 4, pp. 1-6. 